\title{
The golden retriever model of Duchenne muscular dystrophy
}

Joe N. Kornegay

\begin{abstract}
Duchenne muscular dystrophy (DMD) is an X-linked disease caused by mutations in the DMD gene and loss of the protein dystrophin. The absence of dystrophin leads to myofiber membrane fragility and necrosis, with eventual muscle atrophy and contractures. Affected boys typically die in their second or third decade due to either respiratory failure or cardiomyopathy. Despite extensive attempts to develop definitive therapies for DMD, the standard of care remains prednisone, which has only palliative benefits. Animal models, mainly the mdx mouse and golden retriever muscular dystrophy (GRMD) dog, have played a key role in studies of DMD pathogenesis and treatment development. Because the GRMD clinical syndrome is more severe than in mice, better aligning with the progressive course of DMD, canine studies may translate better to humans. The original founder dog for all GRMD colonies worldwide was identified in the early 1980s before the discovery of the DMD gene and dystrophin. Accordingly, analogies to DMD were initially drawn based on similar clinical features, ranging from the X-linked pattern of inheritance to overlapping histopathologic lesions. Confirmation of genetic homology between DMD and GRMD came with identification of the underlying GRMD mutation, a single nucleotide change that leads to exon skipping and an out-of-frame DMD transcript. GRMD colonies have subsequently been established to conduct pathogenetic and preclinical treatment studies. Simultaneous with the onset of GRMD treatment trials, phenotypic biomarkers were developed, allowing definitive characterization of treatment effect. Importantly, GRMD studies have not always substantiated findings from mdx mice and have sometimes identified serious treatment side effects. While the GRMD model may be more clinically relevant than the mdx mouse, usage has been limited by practical considerations related to expense and the number of dogs available. This further complicates ongoing broader concerns about the poor rate of translation of animal model preclinical studies to humans with analogous diseases. Accordingly, in performing GRMD trials, special attention must be paid to experimental design to align with the approach used in DMD clinical trials. This review provides context for the GRMD model, beginning with its original description and extending to its use in preclinical trials.
\end{abstract}

Keywords: Duchenne muscular dystrophy (DMD), Golden retriever muscular dystrophy (GRMD), Animal models, Preclinical studies

\section{Background}

Duchenne muscular dystrophy (DMD) is a devastating Xlinked inherited degenerative muscle disease [1] affecting $\sim 1$ in 4000-6000 boys [2]. Mutations in the $D M D$ gene limit production of the protein, dystrophin, resulting in loss of myofiber membrane integrity and repeated cycles of necrosis and regeneration [1]. Muscle is gradually replaced with fibrous connective tissue and fat, leading to weakness and debilitating contractures. Eventual involvement of

\footnotetext{
Correspondence: jkornegay@cvm.tamu.edu
}

Department of Veterinary Integrative Biosciences, College of Veterinary Medicine and Biomedical Sciences, Texas A\&M University, Mail Stop 4458, College Station, TX 77843-4458, USA

(c) The Author(s). 2017 Open Access This article is distributed under the terms of the Creative Commons Attribution 4.0 International License (http://creativecommons.org/licenses/by/4.0/), which permits unrestricted use, distribution, and reproduction in any medium, provided you give appropriate credit to the original author(s) and the source, provide a link to the Creative Commons license, and indicate if changes were made. The Creative Commons Public Domain Dedication waiver (http://creativecommons.org/publicdomain/zero/1.0/) applies to the data made available in this article, unless otherwise stated. 
autosomal versus X-linked pattern of inheritance. While these animal studies provided useful insight on disease pathogenesis, their overall value was questioned [4].

Subsequently, spontaneous genetically homologous dystrophinopathies have been identified in several mammalian species, including mice and dogs. Because the phenotype of dystrophic dogs more closely mirrors that of DMD, pathogenetic and preclinical treatment studies may better translate to humans. Most canine studies have been conducted in the golden retriever muscular dystrophy (GRMD) model, which occurs due to a spontaneous splice site mutation in the $D M D$ gene. In this review, fundamental early observations that hinted at the membranal nature of both DMD and GRMD are covered first, followed by a discussion of molecular studies that identified the $D M D$ gene and dystrophin protein. Challenges facing physicians and scientists in translating therapies from animals to humans are then discussed, with emphasis on the importance of first and foremost establishing safety. The review concludes with an overview of the role of animal models and, in particular, GRMD in treatment development.

\section{Disease pathogenesis: the membrane theory}

Well before the molecular age allowed identification of disease-causing genes, physicians and scientists relied on clinical clues and their intuition to infer disease pathogenesis. Much early attention focused on the so-called membrane theory of DMD, as stated by Rowland, "The functional genetic fault of DMD affects an enzyme or structural protein which is decreased in amount or rendered functionally abnormal because of an altered amino acid sequence. In either case, the altered protein results in abnormal composition and altered function of muscle cell surface membranes" [4]. The membrane theory originated with the observation that enzymes, such as aldolase and phosphorylase, were decreased in muscle [5] and elevated in serum $[6,7]$. This was presumed to occur because of damage to the myofiber membrane, the sarcolemma. In fact, elevations of creatine phosphokinase (CPK), now typically shortened to creatine kinase (CK), had become particularly useful in the diagnosis of DMD [6]. Additional support for the membrane theory came from ultrastructural studies showing defects in the sarcolemma (Fig. 1) that purportedly allowed enzyme leakage [8-11]. Concomitant influx of calcium was hypothesized to lead to fiber hypercontraction or protease activation, each of which could contribute to the characteristic myofiber (hyaline) necrosis seen in DMD. In support of this mechanistic disease association, the membrane lesions sometimes overlay wedge-shaped areas of focal necrosis, so called delta lesions [10] (see Fig. 4).

In addition to enzyme changes and sarcolemma lesions, electromyography (EMG) provided a third less

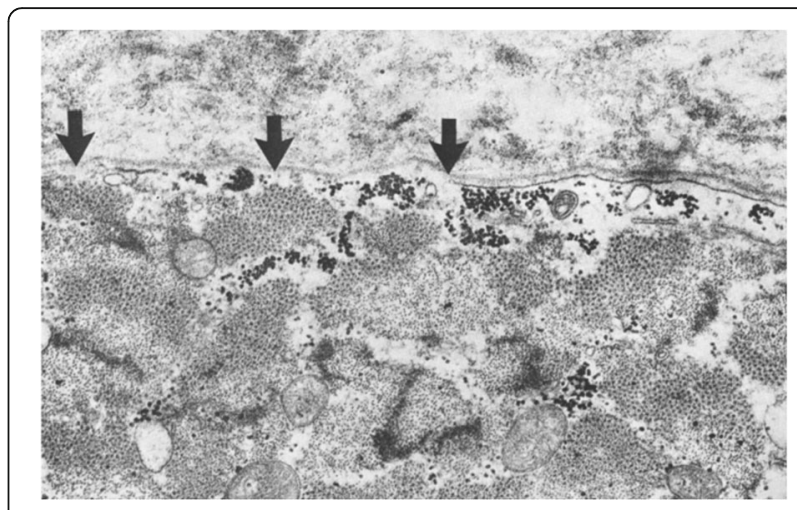

Fig. 1 Characteristic myofiber membrane lesion in DMD. Electron photomicrograph demonstrates lack of continuity of the myofiber (sarcolemmal) membrane (arrows), while the basal lamina remains intact. The myofiber architecture is disrupted subjacent to the membrane lesion. Original magnification 26,000. From reference [8]

discussed marker of potential membrane involvement. As with other myopathies, DMD is characterized by low amplitude, short-duration motor unit potentials, with associated spontaneous activity ranging from fibrillation potentials to complex repetitive discharges (CRDs) [12-15]. The occurrence of CRDs is of particular interest, given their predominance on EMG studies in canine dystrophinopathies (see below). Previously called pseudomyotonia or bizarre high-frequency discharges, CRDs are high frequency spontaneous potentials that begin and end abruptly $[16,17]$ (Fig. 2). This pattern contrasts with true myotonic discharges that wax and wane, creating a characteristic "dive bomber" sound [17]. While spontaneous activity on EMG may occur with either neuropathies or myopathies, CRDs occur preferentially in myopathies [18] and point to myofiber membrane involvement [19]. Buchtral and Rosenfalck reported pseudomyotonic bursts in human progressive muscular dystrophy patients in their 1963 monograph [12] (Fig. 2). Others have shown that CRDs occur more often than additional forms of pathologic spontaneous activity in DMD versus the less clinically severe dystrophinopathy, Becker muscular dystrophy (BMD) (see below), and even more so, when compared to the other dystrophies $[14,15]$. In general, CRDs are thought to occur through ephaptic transmission of action potentials between muscle fibers, although the involved mechanisms are not well understood $[17,20]$. In principle, membrane lesions that limit chloride or enhance sodium conductance into the myofiber could shift the resting membrane potential towards the threshold for depolarization, with associated repetitive electrical discharges [21]. Consistent with this observation, mutations in chloride (CLCN1) and sodium (SCN4A) skeletal muscle channel genes have been incriminated in the myotonias [16]. Moreover, dysregulation of $\mathrm{Na}_{\mathrm{V}} 1.4$, the protein product of SCN4A, leads to increased intracellular sodium and cell death in mdx mice [22], which also express CRDs [23, 24]. 


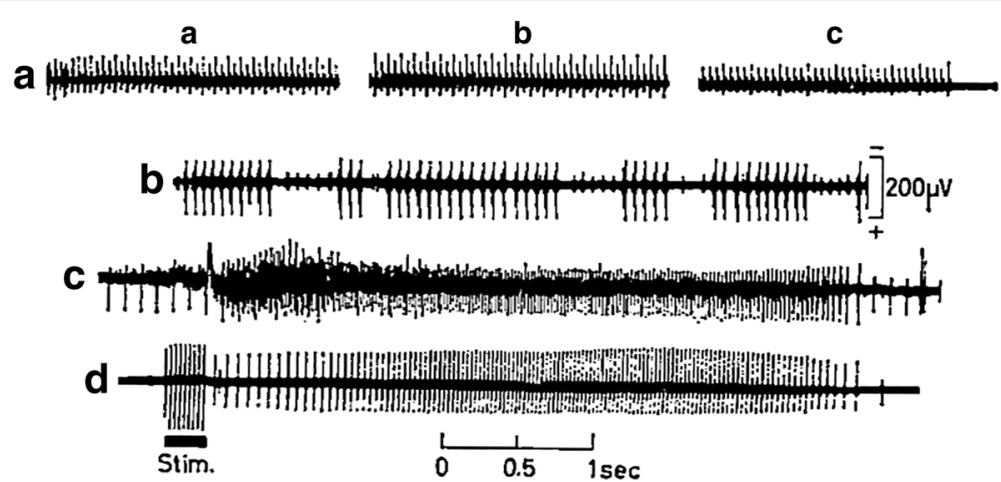

Fig. 2 Spontaneous EMG activity in muscle disease. Activity, termed pseudomyotonic bursts, that begins and ends abruptly, in the hypertrophied calf muscle of a DMD patient $(\mathbf{a}, \mathbf{b})$, contrasts with waxing and waning myotonic activity from a forearm extensor of a myotonic dystrophy patient $(\mathbf{c}, \mathbf{d})$. The activity in a was recorded from two fibers discharging at 22 and 11/s over a 45-s period with the three bursts (a-c) separated by $20 \mathrm{~s}$. Bursts in $\mathbf{b}$ had a frequency of 15/s. Increasing and decreasing activity in c (maximum 50/s) and $\mathbf{d}$ (maximum 35/s) were induced by movement of the concentric recording electrode and direct stimuli, respectively. From reference [12]

\section{The DMD gene, dystrophin protein, and dystrophin-glycoprotein complex}

The mode of inheritance for DMD was long suspected to be X-linked because of the disease's predominance in males. While an X-linked pattern was ultimately corroborated by pedigree studies $[25,26]$, this interpretation was clouded by the rare occurrence of a similar clinical syndrome in girls [27]. Some such cases were thought to occur due to disproportionate inactivation of the normal $\mathrm{X}$ chromosome in female DMD carriers, as was subsequently well documented [28]. Others were associated with autosomal translocations within the Xp21 region of the short arm of the X-chromosome, pointing to this area as a likely site of the $D M D$ gene [29]. This putative site was confirmed when restriction fragment length polymorphisms (RFLPs; markers) cleaved from DNA were shown to flank the Xp21 locus [30]. An analogous association was made with the less severe clinical syndrome of BMD [31]. Following closely on this work, Kunkel et al. capitalized on a DMD patient with a cytogenetically visible Xp21 deletion that also included genes for three other diseases [32, 33]. Several DNA fragments absent from the patient were cloned to provide linkage markers for the $D M D$ locus. In a follow-up multicenter study, DNA from over a thousand DMD and BMD patients was probed using these clones, with $6.5 \%$ showing deletions at the DXS21 locus [34]. Using the DXS21 locus as the starting point, chromosomal walking was employed to map and clone the entire $14 \mathrm{~kb} D M D$ gene transcript [35]. Dystrophin, the $425 \mathrm{kd}$ protein product of the $D M D$ gene, was characterized and found to be absent in both DMD patients and the mdx mouse [36]. Tying matters together further, the molecular basis for DMD and BMD was shown to depend on whether the underlying mutation maintained (BMD; in frame) or disrupted (DMD; out of frame) the three nucleotide (codon) reading frame for amino acids [37]. Subsequent studies have established that deletions (60\%) and duplications (5\%) account for $\sim 65 \%$ of DMD and BMD mutations and that they tend to concentrate in two so-called hot spot areas near the N-terminus (exons 3-7) and within the central rod domain (exons 45-53) [38-41]. Definition of the specific extent and location of the mutation has become critical with the advent of antisense oligonucleotide therapies intended to reestablish the reading frame (see below in the context of canine $D M D$ gene mutations) [42]. In tandem with early studies of the $D M D$ gene, Campbell and Kahl published work that led to a series of comprehensive studies linking dystrophin with additional proteins and sugar moieties to form the dystrophin-glycoprotein complex [43]. A number of other muscular dystrophies subsequently have been causally associated with mutations in genes coding for structural proteins and glycosylating enzymes within this complex $[44,45]$.

\section{The search for a cure}

The approach to DMD treatment can be divided into two periods. The first predated identification of the $D M D$ gene and dystrophin protein when management was largely symptomatic or employed drugs directed at disease mechanisms inferred from pathologic changes. Extending from this period, the second phase has focused on directed genetic and cellular approaches that offer the potential for cure. Soon after the discovery of the $D M D$ gene and dystrophin protein, the "Journal of Child Neurology" published three perspectives from Jan Witkowski [46], Victor Dubowitz [47], and Jerry Lewis [48], the first two commenting as a scientist and clinician and Mr. Lewis as a longstanding champion for the Muscular Dystrophy Association and "Jerry's Kids." Key comments from each of their commentaries are reproduced here: 
This new knowledge has tremendous implications for the physician caring for DMD patients and their families, and it has led to new methods for diagnosis, prognosis, and genetic counseling. In the not-toodistant future, this research may lead to therapies for DMD. Jan Witkowski

Although it may be exciting to speculate on the possibility of gene therapy in muscular dystrophy, it seems extremely unlikely that this could become a reality in the foreseeable future. Victor Dubowitz

I don't pretend to understand the language of science or comprehend the many complex research findings discussed in these articles. But there's a basic, underlying message I do understand - a message of excitement that we've scored long-awaited victories against a disease that cripples and kills thousands of children, and of hope that these victories will soon lead us to a cure or a treatment. Jerry Lewis

Reflecting on these comments in hindsight garnered over 30 years, each appears to have gotten things just about right. As Dr. Witkowski predicted, the discovery of the $D M D$ gene and dystrophin protein has advanced the fields of diagnosis and genetic counseling and set the stage for more directed DMD treatments, to include gene and cell-based approaches. And, who could argue with Jerry Lewis, who pointed to the tremendous energy that these discoveries unleashed. But, Dr. Dubowitz's cautionary note was also prophetic. Progress on genetic therapies has been frustratingly slow, with a number of approaches failing or being delayed by unforeseen complications. The fact that glucocorticoids remain the standard of care for DMD provides stark evidence of the challenges of implementing genetic and cellular therapies $[49,50]$.

\section{The long and winding road to drug approval}

The road to drug approval is often difficult, with less than $20 \%$ of Phase II trials being successful, typically due to either a lack of efficacy or safety concerns $[51,52]$. Failure to demonstrate efficacy is caused, in part, by challenges in accruing sufficient patients to achieve necessary power [53]. This issue is exaggerated with rare (orphaned) diseases such as DMD. The Orphan Drug Act of 1983 provided various Food and Drug Administration (FDA) incentives, including expedited review and delayed approval of competing drugs, to facilitate development of therapeutics [54]. Motivated by these incentives, there has been a marked uptick in approaches directed at Duchenne patients. A total of 206 studies of DMD diagnostic tests and treatment trials in various stages of initial enrollment to termination are currently listed on the NIH Clinical Trials.gov website (https://clinicaltrials.gov/ct2/
results?term=Duchenne+Muscular+Dystrophy\&pg=2) Results of these new treatments have been mixed [49]. On a promising note, ataluren, the first drug approved to specifically target the underlying $D M D$ gene mutation, showed potential benefit in an initial phase $2 \mathrm{~b}$ study [55, 56] and patients are now being enrolled in a larger phase 3-trial (https://clinicaltrials.gov/ct2/show/NCT02090959? term=ataluren\&rank=1). However, other recent clinical trials, including the failure of phophodiester-5 inhibitors to translate to Duchenne and Becker patients $[57,58]$ and ongoing questions surrounding efficacy of the exonskipping strategies $[59,60]$, have illustrated the complexities surrounding treatment development.

\section{Doctor, do no harm}

In treating patients, physicians have been guided by a set of ethical principles that date to ancient Greece and are embodied in the Hippocratic oath. Indeed, some form of this oath is taken by newly graduating physicians and should guide all who practice clinical medicine. While not specifically included in the original oath, newer versions typically include language to the effect of, "first, do no harm." Safety also lies at the heart of the FDA's approval process for an investigational new drug (IND), as detailed in FDA Code of Federal Regulations (CFR) Title 21, Part 312 (accessdata.fda.gov/scripts/ cdrh/cfdocs/cfcfr/CFRSearch.cfm?CFRPart = 312), beginning with preclinical testing in animals and the subsequent phased process for human clinical trials. Smaller populations of human volunteers are first evaluated to establish safety (Phase 1) before larger clinical groups are tested to determine efficacy (Phases 2-4).

Preclinical animal testing has played a critical role in demonstrating drug safety, extending from FDA policies formulated over the past 50 years to the IND protocol used today. Acute, subacute, and chronic dosing studies are required in a rodent and second (often dog) species $[61,62]$. For sake of pediatric populations, emphasis has been placed on the use of analogous juvenile animals to better predict potential developmental side effects (see "GRMD in preclinical trials: experimental design" section below) [63]. The FDA has also recently released rigorous guidelines for gene and cell-based therapies [64, 65]. Germane to this review, these guidelines emphasize choosing animal models likely to demonstrate a biological response, such as immunity, that would be expected in humans. Moreover, disease models were recommended over normal animals because of their greater likelihood to predict the risk-benefit ratio of the investigational product.

\section{The golden retriever model}

\section{Animal models: an overview}

Safety considerations discussed above point to the importance of careful design of preclinical studies, to 
include animal model selection. In this regard, a 1985 National Research Council report emphasized that biological modeling could be by either analogy or homology [66]. Analogy implies a point-by-point relationship between one structure or process to another, while homology suggests a shared evolutionary history and matching DNA makeup. Before the discovery of the $D M D$ gene in 1987, it was not possible to identify true genetically homologous animal models. Investigators had to rely on models that were neither analogous phenotypically nor genetically homologous [3]. Naturally occurring genetic DMD mammalian models have subsequently been defined in mice [67-69], dogs [70], cats [71, 72], and pigs [73]. As would be expected, given inherent biologic differences between quadruped animals and humans, none of these mammalian DMD models are fully analogous clinically. Most notably, mdx mice are mildly affected, with near-normal life expectancy. Dystrophic cats have a curious hypertrophic myopathy and are prone to a malignant-hyperthermia like syndrome [74]. Dogs have a severe phenotype that more closely mirrors that of DMD. But, as discussed below, dystrophic dogs may stabilize after $\sim 6$ months of age and often live well into adulthood [75]. Although knockout and spontaneous dystrophic pigs have not yet been fully characterized, one knock out model had an unexpectedly severe phenotype (Rogers C, personal communication, 2014). The lack of analogy between the phenotypes of different animal models and DMD inherently limits conclusions that can be reached from mechanistic and preclinical studies. A rat model, created by molecularly targeting $D M D$ gene exon 23 , could have advantages over the thus-far described mdx and larger spontaneous mammalian models [76].

Potential DMD treatments have generally been tested initially in the mdx mouse, often establishing proof of concept for the particular approach [77]. Major advantages of the mdx mouse include its consistent phenotype and relatively modest expense, which allows multiple variables to be tested through reasonably powered studies. On the other hand, the mouse's small size limits assessment of scalable variables such as cell migration or drug diffusion [78]. Perhaps even more importantly, mdx mouse preclinical trials have generally not identified treatment complications. This has been particularly problematic with their failure to predict immunologic side effects of gene and cell therapies. These advantages and limitations are essentially reversed for dystrophic dogs. Expense of maintaining dogs limits the number of variables that can be tested and phenotypic variation further reduces the power that can be achieved. With that said, the dog's larger size and outbred nature allows for better modeling of scalable variables such as cell diffusion and the immune response to biologics. A general paradigm has evolved, whereby initial testing is done in mdx mice and, pending positive results, follow-up studies in dystrophic dogs are considered.

\section{Animal models: the two cultures of drug discovery}

Considerable attention has recently been focused on the failure of preclinical treatment trials to translate to human patients. Various reasons have been offered to account for this disconnect. A key factor relates to what has been termed the "two cultures phenomenon" [79]. Put simply, preclinical studies are often as loose as clinical trials are rigorous. Too little attention is paid to basic tenets of experimental design, extending from power analysis of the biomarker used to assess efficacy to the need for blinding $[80,81]$. This problem extends to the level of detail provided on experimental design in grant applications and also to the degree to which it is considered in the review process. Understandably, the review process places considerable emphasis on a proposal's innovative approach and potential impact. Unfortunately, less attention is sometimes paid to experimental design. Canine and other large animal models are particularly vulnerable in this area. Legitimate animal availability and budgetary issues consistently preclude conduct of a perfect study that is sufficiently powered and allows all variables to be considered. Accordingly, large animal studies must be focused and resist the temptation to explore a tangential issue.

\section{Animal models: a change in mindset}

As detailed above, preclinical animal studies help to inform the drug discovery process for both efficacy and safety. Safety is well represented in classical toxicologic assays that demonstrate potential off-target effects of a drug, as with hepatotoxicy. However, safety has often taken a backseat to efficacy in preclinical treatment trials. Investigators seem overly motivated to show that a treatment "works" versus pointing out that it failed or had deleterious consequences. Results that identify limitations of a treatment are said to be "disappointing" and, potentially, not even deserving of publication [81]. One could argue that this is precisely the wrong attitude. The greatest shortcoming of an animal model is not that it failed to demonstrate efficacy but that it failed to identify a potential risk. That it did not identify a worst-case scenario that led to a set of serious side effects. Stated another way, an animal model has failed when it did not identify a risk that caused serious complications in the 131st patient in a phase 3 treatment trial after all had gone well with the first 130 . To address the apparent disconnect between animal and human clinical studies, preclinical investigators must be more rigorous in developing their experimental designs and place more importance on identifying treatment complications. 


\section{Dusty and Rusty}

The GRMD model can be traced to a litter of golden retrievers, three males and one female, born July 21, 1981, outside Athens, Georgia, the home of the University of Georgia. Stiffness and simultaneous advancement of the pelvic limbs (bunny hopping) was noted in all three males at 9-11 weeks of age. Clinical signs of muscle disease were not seen in the dam, sire, or female littermate or in previous or subsequent litters of the dam. However, the same mating was purposely not repeated. A single male sibling from both the dam's own litter and that of the grand dam had similar clinical signs. Cardinet and Holiday reported partial results from histopathologic studies of the male sibling from the dam's litter in their 1979 monograph on canine muscle disease [82]. The sibling from the grand dam's litter was euthanized after only a minimal evaluation and a necropsy was not done.

A veterinarian in private practice near Athens evaluated the dogs and submitted blood for routine analysis through the Veterinary Medical Diagnostic Laboratory at the University of Georgia on September 29, 1981. The most significant abnormality was dramatic elevation of serum CK (U/l) in two of the males, Dusty $(16,770)$ and Rusty $(24,442)$. Values for the other male (798) and female (529) were within normal limits. An inherited degenerative myopathy was suspected, and the owners were given a guarded prognosis. The male dog with the normal CK value died acutely when it was 10 weeks old, and a congenital diaphragmatic hernia compatible with an apparently unrelated syndrome seen in golden retrievers [83] was diagnosed at necropsy. Histopathologic lesions were not seen on assessment of selected skeletal muscles.

Dusty and Rusty were donated to the University of Georgia Veterinary Teaching Hospital on October 16, 1981, with an understanding that breeding might be done to perpetuate the condition. A series of tests, including $\mathrm{CBC}$, serum chemistries, EMG, and muscle biopsies, were subsequently performed over the next 10 months. Results were compatible with a degenerative myopathy that had previously been documented in five other male golden retrievers (Table 1). The condition was called "golden retriever myopathy," in keeping with a tendency for veterinarians to name canine diseases for the breed in which they occur [84]. Dusty and Rusty

Table 1 Additional golden retrievers with degenerative myopathy as of 1988

\begin{tabular}{|c|c|c|c|c|c|c|c|}
\hline $\begin{array}{l}\text { Age at clinical } \\
\text { onset }\end{array}$ & Gender & Clinical signs & CK & EMG & Pathologic lesions & Outcome & Reference \\
\hline 10 days & M & $\begin{array}{l}\text { Body stunting; glossal, shoulder, } \\
\text { and neck muscle hypertrophy; } \\
\text { bradycardia }\end{array}$ & $\mathrm{NE}$ & $\mathrm{NE}$ & $\begin{array}{l}\text { Gross body stunting and } \\
\text { muscle hypertrophy. Skeletal } \\
\text { muscle histologic evidence of } \\
\text { variation in fiber size, hyaline } \\
\text { fibers with calcification, and } \\
\text { basophilia consistent with } \\
\text { regeneration; inflammation } \\
\text { including giant cells; milder } \\
\text { lesions in the heart. }\end{array}$ & $\begin{array}{l}\text { Euthanasia } \\
\text { at } 10 \text { days }\end{array}$ & [88] \\
\hline $\begin{array}{l}6-8 \text { weeks } \\
\text { (two littermates } \\
\text { were described) }\end{array}$ & M & $\begin{array}{l}\text { Stiff gait with progression to a } \\
\text { stilted, shuffling gait by } 3 \text { months. } \\
\text { Fatigue with exercise, occasional } \\
\text { respiratory distress, neck stiffness, } \\
\text { resistance to jaw opening, and } \\
\text { glossal hypertrophy. }\end{array}$ & Elevated & "Myotonia" & $\begin{array}{l}\text { Severe degenerative muscle } \\
\text { disease: myofiber necrosis, } \\
\text { mononuclear phagocytosis, } \\
\text { giant cells, and calcification }\end{array}$ & $\begin{array}{l}\text { Euthanasia at } \\
6-9 \text { months } \\
\text { when the } \\
\text { dogs were still } \\
\text { ambulatory }\end{array}$ & [91] \\
\hline 4-5 months & M & $\begin{array}{l}\text { Generalized muscle atrophy, stiff } \\
\text { gait, dysphagia, stenotic breathing, } \\
\text { exercise intolerance. }\end{array}$ & $\mathrm{NE}$ & CRDs & $\begin{array}{l}\text { Gross muscle atrophy; scattered } \\
\text { necrotic fibers undergoing } \\
\text { phagocytosis, increased } \\
\text { endomysial connective tissue, } \\
\text { calcification of myofibers, } \\
\text { targetoid fibers, and fiber type } \\
\text { grouping; myocardial } \\
\text { degeneration and calcification }\end{array}$ & $\begin{array}{l}8 \text { months at } \\
\text { biopsy; outcome } \\
\text { not given. }\end{array}$ & {$[82]$} \\
\hline 8 weeks & M & $\begin{array}{l}\text { Stiff, shuffling gait; simultaneous } \\
\text { pelvic limb advancement (bunny } \\
\text { hopping); overextension at the } \\
\text { carpus, overflexion at the tarsus, } \\
\text { and abduction of the paws; stifle } \\
\text { adduction; hypertrophy of } \\
\text { proximal limb muscles; mild } \\
\text { vertebral kyphosis; trismus; } \\
\text { drooling. }\end{array}$ & $13,435 \mathrm{IU} /$ & $\begin{array}{l}\text { CRDs and } \\
\text { positive } \\
\text { sharp } \\
\text { waves }\end{array}$ & $\begin{array}{l}4 \text { months: fiber size variation, } \\
\text { hyaline and necrotic fibers with } \\
\text { myophagocytosis; centrally } \\
\text { nucleated fibers; basophilic } \\
\text { fibers consistent with } \\
\text { regeneration. } 8 \text { months: } \\
\text { progressive changes with } \\
\text { mineralization and endoymysial } \\
\text { and perimysial fibrosis; fibers } \\
\text { with chains of central nuclei; } \\
\text { fiber grouping. }\end{array}$ & $\begin{array}{l}\text { Euthanasia at } \\
8 \text { months }\end{array}$ & [93] \\
\hline
\end{tabular}


were moved to the College of Veterinary Medicine at North Carolina State University (NCSU) in the Fall of 1982 for continued assessment. Longitudinal phenotypic studies on these dogs up to 27 and 40 months of age at Georgia and NCSU were reported [85]. Briefly, serum CK was dramatically elevated $(>10,000 \mathrm{U} / \mathrm{l})$ and there were features of both muscle fiber degeneration (hyaline fibers, myophagocytosis) and regeneration (small basophilic fibers) on light microscopy. Persistent spontaneous high-frequency discharges, termed pseudomyotonia in our original paper, were seen on EMG.

Rusty (Fig. 3) was moved to the College of Veterinary Medicine at Cornell University at 41 months of age (see below). Clinical and pathologic data collected until his death at 6 years have been published $[86,87]$.

\section{Early reports of golden retrievers with apparent myopathy (Table 1)}

Meier described a 10-day-old male golden retriever with an apparent myopathy in a monograph on canine muscle disease in 1958 [88]. The dog was born with an enlarged tongue that became bigger over time and "crowded the oral cavity and interfered with normal respiration and nursing." Bradycardia and gross enlargement of the muscles of the neck and shoulders were identified on clinical examination. The most striking features at necropsy were body stunting and muscle hypertrophy. Variation in myofiber size, hyaline fibers with calcification, and myofiber basophilia consistent with regeneration were noted microscopically. Milder lesions were seen in the heart. There was a remarkable inflammatory cell infiltrate that included histiocytes and giant cells. Meier speculated that the findings were consistent with vitamin E deficiency at birth. Obviously, one cannot say definitively that this dog had a dystrophinopathy.

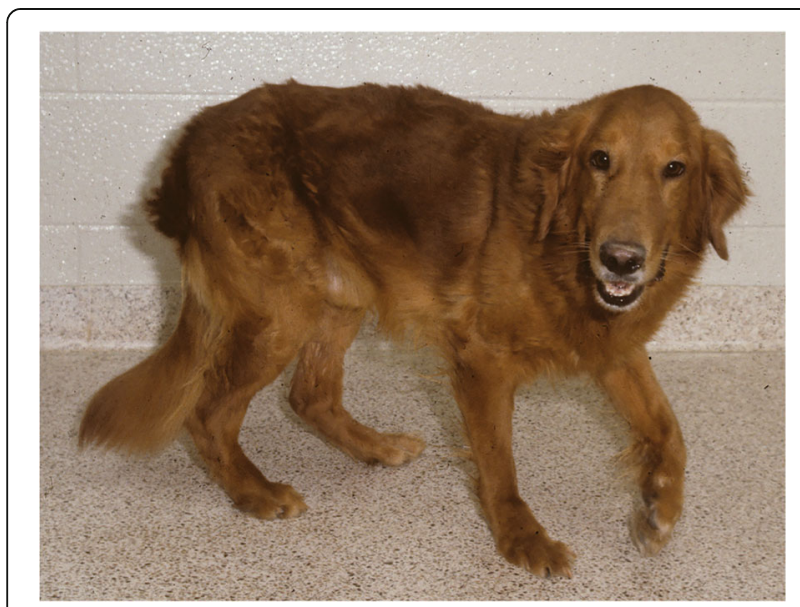

Fig. 3 GRMD colony founder dog, Rusty, at North Carolina State University at $\sim 3$ years of age. Note the relatively mild phenotype characterized primarily by a plantigrade stance
While muscle hypertrophy, especially involving the tongue, is a feature of both DMD and GRMD, generalized muscle enlargement from birth is unprecedented in my experience. Otherwise, this dog bears some resemblance to the fulminant form of disease reported by Valentine et al. [86] and seen by others, in which respiration is compromised at birth. This condition may be analogous to pulmonary hypoplasia seen with congenital diaphragmatic hernia in humans [89]. Normal lung development is dependent on contractile activity of the diaphragm [90] so would likely be compromised in severely affected GRMD fetuses.

Alexander (Sandy) deLahunta provided clinical data on two male golden retrievers evaluated at Cornell University in his 1977 textbook, Veterinary Neuroanatomy and Clinical Neurology [91]. The syndrome was discussed together with a similar condition in Irish Terriers (see below) under a subheading of "Hereditary Myotonic Myopathy in Puppies." Stiff gait was seen at 6 to 8 weeks of age, with progression to a stilted, shuffling gait by 3 months. Other clinical features included fatigue with exercise, occasional respiratory distress, neck stiffness, resistance to jaw opening, and enlargement of the base of the tongue. The dogs were still able to walk at 6 to 9 months when euthanasia was performed. Additional key findings included elevation of serum muscle enzymes, "myotonia" on EMG, and evidence of "severe degenerative muscle disease" on muscle biopsy or necropsy (necrosis of muscle cells, mononuclear phagocytosis, giant cells, and calcification). Reference was made to the more thoroughly studied condition in Irish Terriers, which had been shown by pedigree analysis to be X-linked [92] (see below).

Cardinet and Holliday described an additional 8-monthold golden retriever dog in 1979 [82]. Clinical features were consistent with those described by deLahunta. Highfrequency discharges that waxed and waned were seen on EMG. Histopathologic features included scattered necrotic and/or calcified fibers. Cardinet and Holliday noted that fiber type grouping was consistent with a potential neuropathic component. Another dystrophic golden retriever with similar clinical signs was subsequently identified at Cornell and studied until 8 months of age [93]. Muscle ultrastructure was studied for the first time. Notably, focal wedge-shaped subsarcolemmal "delta" lesions and plasma membrane defects were illustrated (Fig. 4), in keeping with the membrane theory of DMD pathogenesis.

Thus, counting Rusty and Dusty, a total of seven golden retrievers with an apparent primary, inherited myopathy had been reported by the mid-1980s (Table 1). Additional dogs were cited via personal communication in our 1988 paper [85]. Strikingly, all affected golden retrievers were males, suggesting $\mathrm{X}$-linked inheritance and potential genetic homology with DMD. Clinicopathologic evidence of serum CK elevation and small group muscle fiber necrosis and regeneration were also 


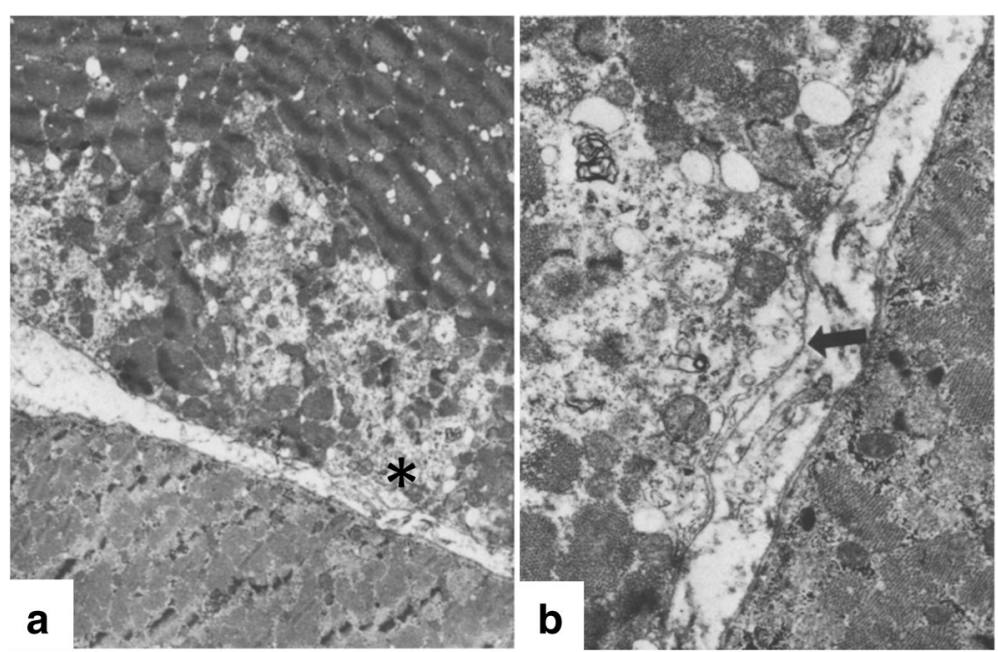

Fig. 4 Myofiber with focal necrosis and membrane lesion in GRMD dog. Electron photomicrographs demonstrating a wedge-shaped subsarcolemmal area of disrupted architecture (a) and higher magnification (b) of the area identified with the asterisk where the myofiber membrane is absent (arrow) and the basal lamina is intact. Original magnification 4500 in $\mathbf{a}$ and 13,500 in $\mathbf{b}$. Modified from reference [93]

consistent with DMD. On the other hand, presence of CRDs on EMG, with associated stilted gait, stiffness, and marked muscle hypertrophy, were more consistent with myotonia.

\section{Cornell and canine X-linked muscular dystrophy}

As detailed above, deLahunta and colleagues at Cornell played a key role in identifying early dystrophic golden retrievers. Barry Cooper, in particular, was motivated to establish a breeding colony of affected dogs and was aware of ongoing studies at NCSU. Rusty was sent to Cornell at 41 months of age, with an understanding that he would be used to establish a colony and then returned for follow on studies at NCSU. However, Rusty developed congestive heart failure at $5 \frac{1}{2}$ years of age and was euthanized at 6 years. So, instead, two obligate carriers (Dys and Trophy) and an affected male (Lewis) produced by Rusty were provided to NCSU to establish a second colony.

The studies by Dr. Cooper and his veterinary colleague, Beth Valentine, were instrumental in defining the phenotype of dystrophic dogs $[86,87,94]$. Rusty was initially bred with two female beagles and a larger retriever cross to produce mixed-breed obligate carriers. These carriers were then bred with Rusty or his male descendants to produce affected dogs. In this sense, GRMD is not a disease of pure-bred golden retrievers. We use the GRMD acronym to refer to the $D M D$ gene splice site mutation present in affected dogs. Other acronyms, such as GSHPMD for German shorthaired pointer muscular dystrophy, refer to additional canine $D M D$ gene mutations. Based on pedigree analysis of the dogs descendant from Rusty at Cornell, a likely recessive X-linked pattern of inheritance was established [95]. Phenotypic features in dogs from the Cornell colony were consistent with those reported in the previously described seven cases and included elevation of serum CK, CRDs on EMG, and histopathologic evidence of grouped muscle fiber necrosis and regeneration. Because this work was done before the $D M D$ gene and dystrophin protein were identified, there was still a question as to whether the disease was a Duchenne genetic homologue. Genetic homology was established with reasonable certainly when neither $D M D$ messenger ribonucleic acid (mRNA) nor dystrophin could be identified in dystrophic dogs [94]. Consistent with the GRMD site splice mutation later identified by Sharp et al. [96] (see below), endonuclease probes did not demonstrate RFLPS that would be expected with a large DNA deletion. Cooper and colleagues termed the disease canine $\mathrm{X}$-linked muscular dystrophy (CXMD).

\section{Canine dystrophinopathies}

Prior to the definition of the $D M D$ gene and dystrophin protein, potentially analogous canine models were proposed based on an apparent pattern of recessive Xlinked inheritance and consistent phenotypic features. In his 1977 textbook [91], deLahunta drew parallels between the condition in golden retrievers and an analogous disease in Irish terrier dogs reported by Wentink et al. [92]. The Irish terrier study included phenotypic data, extending from serum enzymes to necropsies, on a group of five male littermates. Pedigree data, suggesting a pattern of recessive X-linked inheritance, were reported from two prior litters from the same bitch. Serum enzymes, including aldolase and CK, were elevated, in keeping with the membrane theory of DMD pathogenesis. Wentink et al. specifically noted that the dramatic 
increase in CK was typical of DMD. Bizarre highfrequency discharges were seen on EMG, consistent with other canine dystrophinopathies that have since been characterized. Notably, dogs were variably affected, with two having a severe phenotype that necessitated euthanasia between 13 and 20 weeks of age, while another mildly affected dog lived until 16 months before euthanasia. Limb muscles were atrophied but the tongue was hypertrophied. One of the dogs had congenital peritoneopericardial diaphragmatic hernia at necropsy consistent with a syndrome later seen in GRMD dogs. Histopathological lesions were not seen in the hearts, central nervous system, or visceral organs of affected dogs. Based on extensive muscle histochemical and ultrastructural studies, Wentink et al. concluded that mitochondria were abnormal and speculated that uncoupled oxidative phosphorylation could be involved in disease pathogenesis.

Additional apparent dystrophinopathies have since been reported in a number of canine breeds [70, 96-105] (Fig. 5). Phenotypic findings, typical of those seen in GRMD, have included increased serum CK, CRDs on EMG, and histopathologic evidence of grouped muscle fiber necrosis and regeneration. When multiple dogs have been observed, disease severity has varied, in keeping with phenotypic variation seen in GRMD. As with GRMD, paradoxical muscle hypertrophy has seemed to play a role in the phenotype of affected dogs, with stiffness at gait, decreased joint range of motion, and trismus being common features. For the most part, dystrophinopathies in other canine breeds have not been defined beyond immunohistochemical and Western blot studies demonstrating the loss of dystrophin. Relatively few have been studied at the molecular level, with mutations largely paralleling the deletions, insertions, and splice-site mutations seen in DMD [70, 96-105].

The classification of canine dystrophinopathies is complicated by the tendency to associate DMD and BMD with severe and mild clinical phenotypes, respectively. All canine DMD deletions described to date have been out-of-frame, which would predict a severe DMD phenotype. As discussed above and further below, despite having an out-of-frame mutation, GRMD dogs may stabilize and live well into adulthood [75]. The GRMD phenotype could be influenced by spontaneous alternative splicing of the $D M D$ transcript [106], with resultant production of truncated partially functional dystrophin isoforms expressed in so-called revertant fibers. Alternative splicing $[107,108]$ and revertant fibers [109] have also been reported in DMD. Conditions in which truncated isoforms of dystrophin are expressed have been reported in Japanese Spitz and Labrador retriever canine breeds. A $5.4-\mathrm{Mb}$ fragment of the $\mathrm{X}$ chromosome is inverted at the level of intron 19 of the $D M D$ gene and the retinitis pigmentosa GTPase regulator (RTGP) gene of Japanese Spitz dogs [99]. Transcription was demonstrated at the $5^{\prime}$ end but not beyond. A truncated 70 $80 \mathrm{kDa}$ protein, consistent with aberrant expression of Dp71 dystrophin-related protein, was identified. Baroncelli et al. described a 3-year-old male Labrador retriever with what was termed a Becker type syndrome [110]. The dog had a mild phenotype, normal serum CK, and

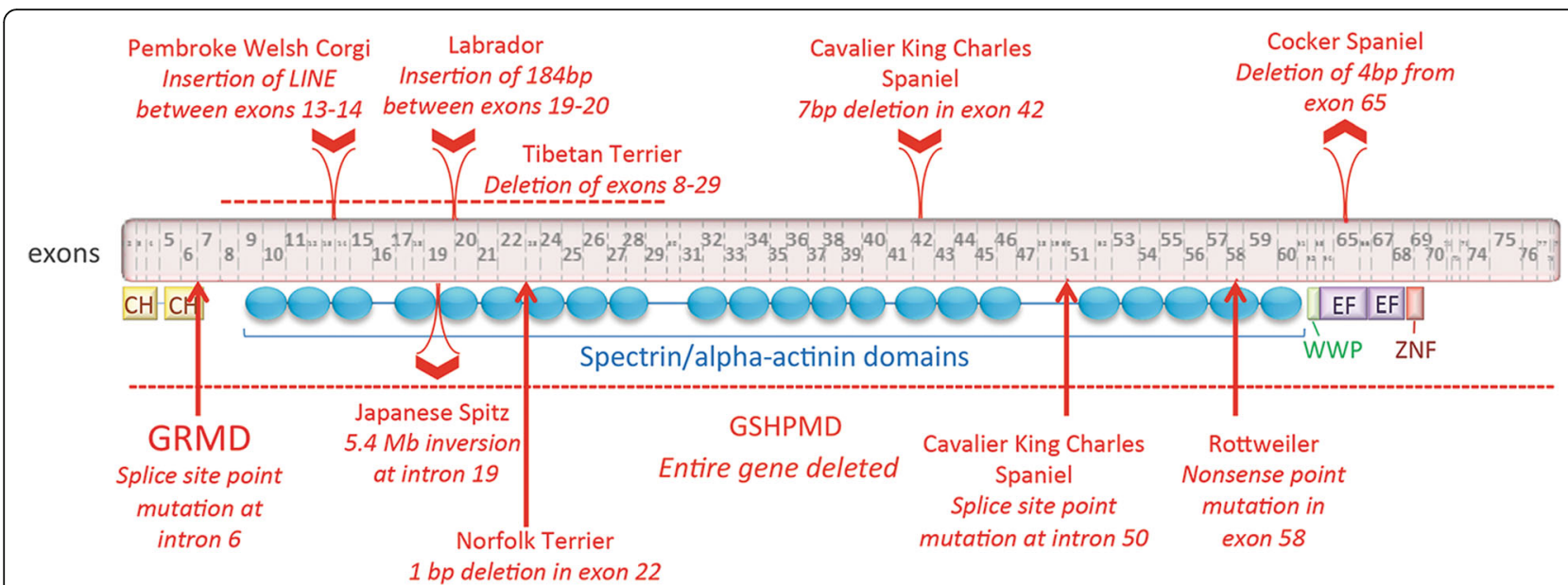

Fig. 5 Canine dystrophin protein (Ensembl protein ID ENSCAFP00000031637), with mutation information for 10 dog breeds with dystrophinopathies. The breeds are Pembroke Welsh Corgi [98], Labrador retriever [97], Tibetan terrier [97], Cocker spaniel [97], golden retriever [96], Japanese Spitz [99], Norfolk terrier [100], German shorthaired pointer [101, 102], two distinct mutations in the Cavalier King Charles spaniel [103, 104], and Rottweiler [105]. CH indicates actin-binding calponin homology domains. The "WWP" domain binds proline-rich polypeptides and is the primary interaction site for dystrophin and dystroglycan. EF indicates members of the EF-hand family domain that stabilizes the dystrophin-dystroglycan complex. ZNF represents a putative zinc-binding domain, ZnF_ZZ is present in dystrophin-like proteins and may bind to calmodulin. All 79 exons are represented. Exons and protein domains are approximately shown to scale. Insertion and deletion mutations are shown above the exons. At the bottom of the figure, the German shorthaired pointer (GSHP) DMD gene deletion and point mutations are identified with a hatched line and arrows, respectively. Modified from reference [70] 
widespread immunohistochemical evidence of dystrophin expression. Immunoblotting revealed two bands consistent with rod-domain and carboxyl-terminus fragments. The molecular mutation was not identified.

Similarly, in another report, Labrador retrievers with no dystrophin had increased serum CK and dystrophic lesions on biopsy but no clinical evidence of myopathy [111]. A somewhat analogous situation exists in German Shorthaired pointers that have a relatively mild phenotype even through the entire $D M D$ gene is deleted [101, 102, 112]. Genetic mechanisms other than frame shift must underlie milder (or more severe) phenotypes in dystrophic dogs. A mild phenotype in two so-called escaper GRMD dogs from one of the Brazilian colonies was associated with a $G>T$ mutation in the promoter region of the Jagged1 gene [113]. Given that this substitution was apparently introduced by an outcross, the Jagged 1 mutation would not necessarily be found in other GRMD colonies. We routinely see mildly affected GRMD dogs that live beyond 3 years of age. In testing done to date, none of these dogs have had the Jagged 1 mutation. Importantly, the original founder dog for all GRMD dogs worldwide, Rusty, lived until 6 years when he developed congestive heart failure and was euthanized [86, 87]. Using Rusty as a benchmark, the GRMD phenotype actually appears to have worsened over time, potentially due to excessive inbreeding and concentration of the effects of genetic modifiers. The genetic basis of phenotypic variation is a subject of active research in my laboratory, with a recent genome wide association study (GWAS) identifying several potential candidate genes that could influence disease phenotype [114].

With the advent of molecular therapies, particular interest has been focused on certain so-called hot spot areas at exons 3-7 and 45-53 of the DMD gene (see above). In GRMD and the further outbred condition, canine X-linked muscular dystrophy in Japan $\left(\mathrm{CXMD}_{\mathrm{J}}\right)$ [115], an mRNA processing error results from a single base change in the $3^{\prime}$ consensus splice site of intron 6 . Exon 7 is consequently skipped during mRNA processing [96]. The resulting transcript predicts that the dystrophin reading frame will be terminated within its $\mathrm{N}$-terminal domain in exon 8 . The dystrophin reading frame can be reestablished using antisense oligonucleotides that target exons 6 and $8[42,116]$. With regard to the even more clinically relevant exon 45-53 hot spot area, Cavalier King Charles spaniels have a G-T missense mutation in the $5^{\prime}$ consensus splice site of intron 50 that results in deletion of exon 50 [103]. Antisense oligonucleotide-mediated skipping of exon 51 restored the reading frame and protein expression in cultured myoblasts from an affected dog. As mentioned above, the fascinating $D M D$ gene deletional mutation in the German Shorthaired pointer breed bears particular mention. The entire $D M D$ gene is deleted in affected dogs
$[101,102]$, thus eliminating the possibility of alternative splicing and the confounding effects of revertant fibers.

\section{GRMD in preclinical trials: overview}

Rather than repeat recent reviews of GRMD preclinical trials and biomarkers [77, 97], this discussion will focus on three areas: (a) the overall preclinical approach to DMD treatment development; (b) nuances of GRMD disease progression that must be considered in experimental design; and (c) cautionary lessons learned from prior GRMD treatment studies.

The DMD research community is fortunate to have two well-defined genetically homologous animal models that can be used in tandem to advance therapy development. Mdx mice should logically be employed for initial in vivo preclinical experiments. Studies that fail to demonstrate potential efficacy bode poorly for translation of the therapeutic strategy to humans and could provide a logical "stopping point" for continued development. Alternatively, if $\mathrm{mdx}$ findings are encouraging, consideration should be given to extending the work to GRMD or another canine model. However, in reality, studies in dogs are limited because of their availability and expense. When dystrophic dogs have been studied, results from $\mathrm{mdx}$ mice have not been consistently reproduced. In such cases, inherent species differences preclude saying whether the mouse or dog would better predict the ultimate outcome in humans. But, at the very least, a failure to reproduce favorable data in both species should raise concerns and prompt reassessment of the therapeutic approach.

The experimental design and outcome parameters used in preclinical trials should mirror those anticipated in human studies. Importantly, in the context of the "two cultures phenomenon" discussed above, animal studies should be rigorous, with close attention to issues such as group size, use of proper controls, and blinding. In a recent review of mdx and GRMD preclinical trials [77], we offered the following guidelines for improving translation of animal findings to humans:

- Design studies with sample sizes that are sufficiently powered to detect treatment effects with the outcome parameters used.

- Follow randomization and blinding procedures, including who is blinded and when.

- Provide details of the statistical methods used for data analysis and report all the results for each analysis.

- Develop reliable and sensitive primary and secondary endpoints for the animal model used.

- Independently validate treatment efficacy results in another laboratory. 
- Validate treatment efficacy in two species (e.g., mdx mouse and GRMD dog for DMD) whenever possible.

\section{GRMD in preclinical trials: experimental design}

For the sake of GRMD trials, we have long focused on the 3- to 6-month age period during which clinical signs progress particularly rapidly. Based on an epidemiologic study by Patronek et al. [117], the first year of a golden retriever's life roughly equates to 20 years of a human. Therefore, the GRMD age quartiles of 0-3, 3-6, 6-9, and 9-12 months would logically correspond to $0-5,5-$ $10,10-15$, and $15-20$ years of DMD. In comparing the relative severity of disease over these age periods, GRMD and DMD generally progress analogously up to 6 months (GRMD) [75] and 10 years (DMD) $[118,119]$ (Fig. 6). While GRMD pups may be weak at birth and require dietary supplementation [120], they tend to stabilize around 2 weeks and are mildly affected up to 3 months, when more progressive clinical involvement is seen. Similarly, DMD boys have relatively stable disease up to 6 years of age and then progressively decline for the next 5 years [118].

In our experience, the GRMD and DMD phenotypes diverge after 6 months and 5 years, respectively, with dystrophic dogs tending to stabilize and boys inexorably progressing [75, 118-130]. Even though GRMD dogs in our colony progress markedly up to 6 months, they rarely lose the ability to walk, which would be analogous to becoming confined to a wheelchair in DMD, and often live well into adulthood. With this said, other laboratories have reported a more severe GRMD phenotype. For instance, $\sim 25 \%$ of GRMD dogs produced in the colony at Alfort in France lose ambulation by 6 months [131]. In a similar vein, GRMD dogs in the Brazilian colony directed by Mayana Zatz generally die within the first 2 years of life [113]. Notably, both the French and Brazilian colonies were derived from the same founder dog, Rusty (see above), identified by our group in 1981. This distinction in phenotypic severity likely occurs due to the relative role of genetic modifiers in each colony, potentially being concentrated by inbreeding or introduced by outbreeding. As an example, inbreeding tends to worsen the phenotype of GRMD pups [120].

Planning and interpretation of (pre)clinical trials in both DMD and GRMD is confounded by variable disease progression among individuals. As with the differing phenotypes seen in GRMD colonies, DMD phenotypic variation likely occurs due to genetic modifiers. Polymorphisms in two genes, secreted phosphoprotein 1 (SPP1) (osteopontin) and latent transforming growth factor $\beta$ binding protein 4

\begin{tabular}{|c|c|c|c|c|}
\hline CM & $\begin{array}{l}\text { Limited data; subclinical } \\
\text { ECG conduction } \\
\text { changes }[121]\end{array}$ & $\begin{array}{c}\text { Abnormal ECG conduction } \\
\text { by 10 years: } \uparrow \text { QT:PQ ratio } \\
\text { (cardiomyopathic index) } \\
\text { [122] }\end{array}$ & \multicolumn{2}{|c|}{$\begin{array}{l}\text { Increasing incidence of clinical cardiac disease (28\% } \\
\text { before } 18 \text { but } 57 \% \text { afterwards) [122]]; } \\
\text { diastole predate systole changes [123] }\end{array}$} \\
\hline SM & $\begin{array}{l}\text { Delayed milestones } \\
{[124]}\end{array}$ & \multicolumn{2}{|c|}{$\begin{array}{l}\text { DMD - lose ambulation by 12-13 yrs; BMD - walk past } \\
\text { 16 yrs; Intermediate - 12-16 yrs [125] } \\
\text { Uniform progression 5-13 yrs [119]; } \\
\text { Severe progression after } 8 \text { yrs [118] }\end{array}$} & $\begin{array}{l}\text { Progressive weakness, } \\
\text { muscle atrophy and } \\
\text { contractures }\end{array}$ \\
\hline & & \multicolumn{3}{|c|}{ Progressive respiratory disease [126] } \\
\hline & 0-5 Yrs & 5-10 Yrs & 10-15 Yrs & $15-20$ Yrs \\
\hline \multicolumn{5}{|c|}{ Duchenne Muscular Dystrophy } \\
\hline CM & $\begin{array}{l}\text { ECG changes ( } \uparrow \text { QT } \\
\text { ratio) by } 3 \text { mos [127] }\end{array}$ & $\begin{array}{l}\text { Echo changes ( } \downarrow \text { LVEDV } \\
\text { and IVESV) by } 6 \text { mos [127] }\end{array}$ & \multicolumn{2}{|c|}{$\begin{array}{l}\text { Cardiac phenotype is stable, with no evidence of } \\
\text { congestive heart failure and normal LVEF } \\
{[127,128]}\end{array}$} \\
\hline SM & $\begin{array}{l}\text { Neonatal respiratory } \\
{[129] ; \Downarrow \text { weight gain; }} \\
\text { flexor weakness }[130]\end{array}$ & $\begin{array}{l}\text { Marked progression; } \\
\text { postural changes; } \\
\text { extensor weakness [130] }\end{array}$ & \multicolumn{2}{|c|}{$\begin{array}{l}\text { Skeletal muscle phenotype tends to stabilize; many } \\
\text { GRMD dogs live well into adulthood }\end{array}$} \\
\hline & 0-3 Mos & 3-6 Mos & 6-9 Mos & 9-12 Mos \\
\hline \multicolumn{5}{|c|}{ Golden Retriever Muscular Dystrophy } \\
\hline
\end{tabular}

Fig. 6 Comparative disease course of GRMD based on the relative equivalency of the first year of a golden retriever's life and initial 20 years of a human's. The two periods are divided into quartiles, e.g., 0-3 months of GRMD paralleling 0-5 years of DMD, with signs of the skeletal myopathy (SM) and cardiomyopathy (CM) listed for each period [118-130]. Note, the GRMD clinical course from 0-6 months largely parallels that of DMD over the 0-10 year period. However, the GRMD and DMD phenotypes then dramatically diverge, with GRMD dogs often stabilizing and DMD continuing to progress. SM skeletal myopathy, CM cardiomyopathy, LVEDV and LVSDV left ventricular end diastolic and systolic volumes, LVEF left ventricular ejection fraction. Modified from reference [75] 
(LTBP4), have been shown to influence the DMD phenotype [132]. Per the discussion above, Vieira et al. identified the Jagged1 gene as a modifier of the GRMD phenotype [113]. We recently published results of a GWAS that defined a number of genes associated with phenotype [114].

For local (intramuscular) or regional (single limb) therapeutic approaches, the opposite untreated limb can serve as a control. With systemic treatments, it is difficult to distinguish a treatment effect from inherently mild clinical disease. Speaking generally, the number of subjects required to establish benefit tracks directly with the standard deviation of the outcome parameter being used and inversely with the relative benefit anticipated. In a somewhat sobering review, Brooke et al. concluded that for a DMD clinical trial intended to "test a drug which might slow the disease to $25 \%$ of its original rate of progression, two groups (placebo and treatment) of 40 patients each would have to be followed for a year" [118]. Such a study typically determines the longitudinal effect of a treatment by comparing baseline and end-ofstudy values. This helps to remove the confounding effect of phenotypic variation because each individual essentially becomes his own control. In principle, even more cases would be required if only data from a final outcome parameter were compared between control and treatment groups.

Power analysis has been used on a limited basis to assess GRMD preclinical biomarkers, with only tibiotarsal joint (TTJ) tetanic torque and the 6-minute walk test (6MWT) being evaluated. The power analysis in our TTJ study anticipated that a single measurement would be done at the end of treatment and compared with a value from a control group [130]. Data for TTJ tetanic flexion torque showed that groups of 15 and 5 GRMD dogs would be necessary to demonstrate differences of 0.2 and 0.4 at 6 months, with associated powers of 0.824 and 0.856 . Based largely on these natural history data, we have typically included 5 or 6 dogs in our GRMD preclinical trials. However, the natural relative recovery of TTJ flexion torque between 3 and 6 months complicates its use in GRMD preclinical trials [130]. Extension values decline over this same period but tend to vary more markedly among dogs, necessitating larger group sizes to establish significance. With more careful monitoring of inbreeding coefficient for sire-dam pairs in our colony, the overall GRMD phenotype is now less severe and not as variable as it was at the time the TTJ torque data were published [130]. A subsequent trial of prednisone in GRMD dogs demonstrated therapeutic benefit of $\sim 60 \%(p<0.05)$ for extension torque using groups of 6 treated and 10 untreated GRMD dogs [133].

For sake of the 6MWT, GRMD dogs walked significantly shorter distances than normal littermates at 6 and 12 months, generally supporting its use in preclinical trials [134]. We also determined that percent increase in CK after the 6MWT was higher in GRMD versus normal dogs, providing an additional potential biomarker. With this said, neither the 6MWT nor CK percent increase was particularly sensitive. Assuming a group size of 6 each for treated and control GRMD dogs, power analysis revealed that an $80 \%$ increase in mean height-adjusted distance walked or 55\% decrease in mean post-exercise CK would be necessary to achieve a desired power of $80 \%$.

As with longitudinal DMD trials, a GRMD study comparing values at baseline ( 3 months) and end of treatment (6 months) would lessen the effects of phenotypic variation, reducing the number of dogs required. Ideally, treatment groups would also be balanced between mildly and severely affected individuals, based on an early biomarker that tracks with disease. In a GRMD study focused on identification of early disease biomarkers, increased numbers of a subset of circulating $\mathrm{T}$ cells and decreased stride frequency on accelerometry at 2 months strongly associated with more severe clinical disease at 6 months [131]. While independent control groups for each preclinical trial should ideally be assessed, budgetary and animal number limitations may necessitate the use of natural history controls. In one such study, TTJ extensor torque and other indices were improved in six GRMD dogs treated with a nuclear factor kappa-lightchain-enhancer of activated B cells (NF- $\mathrm{kB}$ ) inhibitor compared to an independent control group [135].

Just as the overall disease course for DMD patients and GRMD dogs varies, individual muscles also have different patterns of progression. Proximal muscles are classically affected in DMD, with further selective involvement of extensors versus flexors. Muscles, such as the quadriceps, that undergo eccentric contraction are particularly vulnerable [136]. Differential muscle involvement was well illustrated in our natural history TTJ torque study, with flexors being preferentially affected at 3 months and extensors at 6 months [130]. Pointing to the challenges one faces in analyzing functional data, the prednisone-treated GRMD dogs discussed above had a paradoxical decrease in flexor torque. This presumably occurred because of a reduction in early necrosis that otherwise would have led to functional flexor hypertrophy [133]. A similar decrease in flexor torque was seen in another study of GRMD dogs treated with prednisone and cyclosporine [137].

The pattern of differential involvement among skeletal muscles extends to the heart, which has a much later onset of clinical disease. Reasons for preferential disease of skeletal muscles or sparing of the heart are unclear but likely also involve different patterns of gene expression. Through a collaboration with investigators at Vanderbilt, we showed that brain-derived neurotropic factor (BDNF) is preferentially increased in 
young GRMD dogs, perhaps in keeping with a palliative cardiac effect. Moreover, BDNF levels tracked with increased ejection fraction in DMD patients [138]. The relatively late onset of cardiac dysfunction complicates preclinical GRMD studies done over the 3- to 6-month age period. Definition of cardiac biomarkers that would distinguish early subclinical disease is an active area of investigation for my laboratory.

Results of DMD [118] and GRMD [120, 139] functional tests track and correlate with each other, providing some assurance that they are valid markers of disease and can be used to document benefit. For sake of GRMD, mildly affected dogs have proportionally larger TTJ angles and tetanic extensor torque. In addition, cranial sartorius circumference measured at the time of surgical biopsy is proportionally smaller. The opposite pattern is seen in severely affected dogs. On the other hand, 6MWT results from a much smaller group of GRMD dogs did not correlate with other tests, causing concern about this test's reliability [134].

\section{GRMD in preclinical trials: cautionary lessons Pharmacologic approaches}

In developing drug therapies for DMD, approaches have been based on somewhat intuitive assumptions that targeting secondary effects of dystrophin loss, like inflammation, myofiber necrosis, and muscle atrophy, would have benefit. While such treatments are logical, they may inherently compromise or augment ongoing homeostatic mechanisms and potentially do more harm than good. Studies in the GRMD dog have sometimes brought side effects into clearer focus, potentially allowing the particular treatment to be modified.

Anti-inflammatories Glucocorticoids, such as prednisone, have become the standard of care for DMD [140, 141], but also cause a range of side effects [140, 142]. We were motivated to study the effects of prednisone in GRMD dogs to establish a baseline for comparing other treatments and to explore alternative dosage regimens that might not be practical in DMD. The study employed a variation of what has become our standard approach to preclinical studies, with dogs being dosed daily from 2 to 6 months of age at either 1 or $2 \mathrm{mg} / \mathrm{kg}$ [133]. While this dose is higher than the typical regimen of $0.75 \mathrm{mg} / \mathrm{kg} /$ day used in DMD [140, 141], care must be taken in extrapolating drug dosages among species. Body surface area takes into account variables such as drug metabolism and, therefore, offers a better guide than body weight in considering appropriate dosing [143]. Several functional and histopathologic biomarkers were compared between treated and control GRMD dogs at 6 months. Although a dose-related increase in TTJ extensor force was seen, there was a paradoxical decrease in flexor values. The reduced flexor force was attributed to a reduction in early necrosis and a less pronounced regenerative response that would otherwise have led to functional hypertrophy. Dogs in the $2 \mathrm{mg} / \mathrm{kg}$ group also had dramatic myofiber mineralization, potentially due to decreased clearing by macrophages. A subsequent GRMD study by another group of combined prednisone, again at $2 \mathrm{mg} / \mathrm{kg}$, and cyclosporine produced similar results [137]. The fact that high dose prednisone has deleterious effects is not surprising and consistent with broader side effects of the drug. The differential effect on flexor and extensor function is more concerning because of the potential that this could translate to DMD patients. As discussed further below in section "Myostatin inhibition", treatments that cause differential extensor and flexor muscle improvement or decline could aggravate preexisting contractures and postural instability.

Prednisone acts, in part, by inhibiting the NF- $\mathrm{kB}$ signaling pathway [144], which is activated in DMD [145]. Accordingly, this pathway has been targeted in preclinical DMD studies. We conducted a GRMD trial that built on prior mdx mouse experiments in which the Nemo Binding Domain (NBD) peptide was used to inhibit NF- $\mathrm{kB}$ signaling [135]. As with the prednisone study, treatment began at 2 months of age and extended for 4 months, with dogs being dosed intravenously three times weekly and studied at 6 months using several biomarkers. Results paralleled those seen with prednisone, in that TTJ extensor force was increased in treated versus control dogs but flexor values were decreased. Of greater concern, NBD administration over time led to infusion reactions in both treated GRMD and wild-type dogs, pointing to the potential for recombinant proteins to induce an immune response.

Inhibition of protein degradation Given that DMD is predominantly a muscle-wasting disorder, degradative enzymes of the ubiquitin-proteasome (UPS) and calpain systems have been targeted therapeutically. Promising results have generally been achieved in the mdx mouse with inhibition of the UPS [146] but not the calpain system [147]. In a GRMD study, only about half of the muscles studied had increased calpain activity and most actually had decreased proteasome activity [148]. Of greater concern, numerous UPS components were decreased in the heart, suggesting that pharmacologic inhibition of these systems in DMD could have unintended deleterious consequences. Not surprisingly, GRMD dogs treated with a novel calpain inhibitor did not improve [149].

Myostatin inhibition Inhibition of the myostatin gene (growth and differentiation factor 8), a key negative 
regulator of muscle growth [150,151], offers another approach to reverse muscle atrophy. Mdx mice in which myostatin was knocked out [152] or postnatally inhibited [153] had a less severe phenotype. Data from normal [154] and GRMD [155] dogs seemed to substantiate potential value of myostatin inhibition. However, likely reflecting feedback mechanisms, myostatin gene levels are already markedly lower in DMD patients [156], $\mathrm{mdx}$ mice [157], and GRMD dogs [139], raising questions about whether further inhibition is desirable. Such concerns were substantiated by a study in our colony in which GRMD dogs were bred with whippets carrying a myostatin gene mutation. We expected that myostatin heterozygous GRMD dogs (GRippets) would have an improved phenotype, consistent with the prior mdx work. Surprisingly, the GRippets had more severe postural changes than their dystrophic myostatin-wild-type littermates, apparently due to differential effects on agonist and antagonist muscles. For almost all muscles, the degree of atrophy or hypertrophy in GRMD dogs was more pronounced in the GRippets (Fig. 7) [158]. In keeping with studies showing that myostatin is already downregulated in GRMD, mRNA and protein levels did not differ between the two groups. For sake of interpreting these data, it is critical to recognize that findings from a study in which myostatin was downregulated in utero will not necessarily extrapolate to postnatal treatments. But, these findings emphasize that the dystrophic body is already motivated to downregulate myostatin and that the effects of inhibition on muscle mass will not necessarily be uniform.

\section{Cell therapies}

Therapies using muscle-derived or pluripotent stem cells provide a direct means to replace muscle. Because of their outbred nature, dogs are more likely than mice to model the immune response to cell-based therapies.
Indeed, as discussed further below, the dog has proven superior to even primates in modeling host versus graft disease in bone marrow transplantation. Thus far, the most notable stem cell approach for DMD involved intramuscular transplantation of satellite cell-derived myoblasts from normal individuals into dystrophic muscles. Based on proof of principle studies in the $\mathrm{mdx}$ mouse [159], several human trials were instituted, with largely disappointing results $[160,161]$. Most transplanted cells probably died due to the combined effects of poor blood supply and immune rejection; those that survived demonstrated limited migration [162-164]. We characterized canine myoblasts [165] and conducted analogous transplantation studies in the GRMD model during the 1990s. Presumably because of these same limitations, little implantation of donor cells was demonstrated. Failed translation from mice to humans (and dogs) may have related to variables influenced by scale, such as cell migration [78]. With this lack of success in GRMD, we developed a separate model system, in which muscles of normal dogs were injected with a mix of myoblasts and the toxin notexin. While myoblast implantation and differentiation was achieved, providing some hope for the overall approach, further studies have not been done [166].

Given the early disappointing results of myoblast transplantation and the inherent limitations of localized cell therapy to achieve meaningful benefit, considerable interest has focused on other stem cells that could potentially be delivered systemically. Bone marrow transplantation was a natural candidate, and initial findings were encouraging. In two separate studies from Gussoni et al., dystrophin expression and donor-derived myonuclei were demonstrated in transplanted $\mathrm{mdx}$ mice [167] and a DMD patient who received a bone marrow transplant for concomitant severe combined immune deficiency [168]. Nonetheless, in a follow-up study using the $m d x 4 c v$ mutant that lacks revertant fibers, myofiber dystrophin

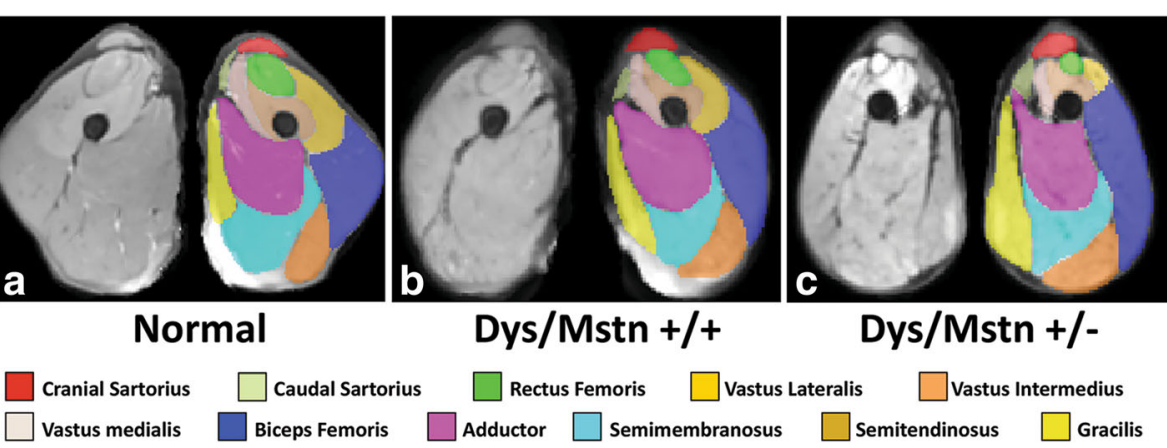

Fig. 7 Averaged MRI segmentation of dogs with variable GRMD and myostatin (Mstn) genotypes. T2-FS MRI images of pelvic limb muscles in the transverse plane at the level of the midthigh are shown in non-dystrophic control (a), dystrophic GRMD, wild-type Mstn+/+ (b) and GRMD, heterozygous null Mstn $^{+-}$(GRippet) (c) dogs. Note the proportional enlargement of the sartorius and hamstring muscles and the associated atrophy/hypoplasia of the quadriceps femoris of the GRMD, wild-type $\mathrm{Mstn}^{+/+}$dogs, relative to the non-dystrophic control dogs, and the even more dramatic differential size of these muscles in the GRippet Mstn ${ }^{+/-}$dogs. From reference [158] 
expression never exceeded $1 \%$ over the 10 -month posttransplant period [169].

As noted above, normal dogs have played a major role in the development of bone marrow transplantation as a reliable therapy, with many of the pioneering studies being done at the Fred Hutchinson Cancer Research Center in Seattle [170]. Thus, the Seattle group was particularly well situated to explore the utility of bone marrow transplantation in dogs with muscular dystrophy. To this end, GRMD/CXMD carriers from the University of Missouri and Cornell were used to establish a colony in Seattle. In a subsequent study, dystrophic dogs with allogenic bone marrow engraftment did not have increased dystrophin-positive fibers, wildtype dystrophin RNA, or donor-derived myonuclei [171].

Although results of bone marrow transplantation have thus far been disappointing, other stem cell therapies have been more encouraging. The GRMD model has been increasingly utilized in these studies, with generally positive findings being reported in 2016, alone, for mesoangioblast [172], adipose mesenchymal [173], and muStem [174] cells. Despite these promising results, analogous studies have not yet been translated to DMD patients [175]. Much as with bone marrow transplantation, the dog's outbred nature has been ideal for defining potential immunologic adverse effects. Considering that myoblasts may elicit an immune response due to both major histocompatibility complex (MHC) and non-MHC antigens [176], most stem cell studies in dystrophic dogs have employed immunosuppressive regimens. Findings from these studies have been confounded by the potential for anti-inflammatories to have an independent beneficial effect. This conundrum arose in a 2006 study in which GRMD dogs treated systemically with mesodermal stem cells derived from the vascular wall, so called mesoangioblasts, had dystrophin expression [177]. Functional improvement in these dogs was questioned, given that the benefit could have occurred due to immunosuppression [178]. Indeed, in a follow-up report, GRMD dogs treated with cyclosporine and prednisone alone had analogous improvement [137]. Another study of MuStem cells contrasted functional outcome variables in immunosuppressed and control dogs and found that dogs treated with stem cells had greater therapeutic benefit [179].

Due to the confounding effect of anti-inflammatory drugs, some subsequent stem cell studies in dystrophic dogs have foregone immunosuppression, choosing instead to match donor-recipient pairs for the canine MHC, the dog leukocyte antigen [173, 180, 181]. Cell implantation and at least minimal dystrophin expression have been achieved in these dogs, with minimal or no adverse immunologic response. Another recent study offers an additional cautionary note [182]. Non-immunosuppressed GRMD dogs were treated three times intra-arterially with autologous CD133+ cells engineered with a lentivirus cassette to skip exons 6-8 and, thereby, restore the mRNA reading frame. Timed function biomarkers stabilized or improved in treated versus control GRMD dogs until the third injection, after which a precipitous decline was seen. This deterioration was attributed to an adaptive immune response aggravated by dystrophin acting as a neoantigen, analogous to a reaction seen in a DMD adeno-associated virus (AAV)-micro-dystrophin gene therapy trial (see below).

\section{Genetic therapies}

Genetic therapies have included AAV-mediated insertion of a truncated mini/micro-dystrophin to fit the vector's limited $\sim 4.5 \mathrm{~kb}$ carrying capacity, antisense oligonucleotides to induce exon skipping and reestablish the dystrophin reading frame, agents to read-through stop codon mutations, and replacement of dystrophin at the sarcolemma with surrogates such as utrophin. Studies in the $\mathrm{mdx}$ mouse have generally demonstrated efficacy and safety of these strategies. Some therapies have subsequently been extended to the GRMD model, providing further proof of concept [77, 97] (see discussion under canine dystrophinopathies above). Data from dystrophic dogs supported the antisense approach, and side effects were not seen [116, 183-186]. But, even with supportive mdx and GRMD preclinical data, human trials have thus far been inconclusive $[59,60]$.

Therapies employing AAV-mini/micro-dystrophin constructs should, in principle, offer similar therapeutic benefits and potential side effects as those employing exon-skipping strategies. With that said, while supportive data have again been demonstrated, greater safety concerns have been identified. Initial alarm was caused when localized (intramuscular) treatment elicited an immune response to either AAV capsid antigen [187] or dystrophin serving as a neoantigen [188] that could be blocked with immunosuppression [189]. Providing encouragement, dystrophin expression was demonstrated after intramuscular injection of an AAV-micro-dystrophin construct without immunosuppression in a single dystrophic dog [190]. And, in another study, immunosuppressed dystrophic dogs treated by intramuscular injection with AAV-microdystrophin had improved force and lower eccentric contraction decrement (ECD) despite a nonspecific lymphocytic infiltrate [191].

Interestingly, the immune response has generally been less pronounced with subsequent regional limb and systemic therapies, potentially because of a dilutional effect on the causative antigen [97]. However, one GRMD dog treated with AAV-mini/micro-dystrophin by regional limb delivery by my group in collaboration with Xiao Xiao at the University of North Carolina-Chapel Hill had increased signal intensity on MRI compatible with 
edema 3 months after treatment, and the level of dystrophin expression was actually higher in the contralateral limb (Kornegay JN and Xiao X, unpublished). This likely reflected the combined effects of dampened dystrophin expression due to the immune response and leakage at the tourniquet to allow systemic delivery. Given the generally promising results of regional limb delivery in GRMD dogs, phase 1-safety studies using saline versus active construct have been completed in both the lower [192] and upper [193] extremities of adult muscular dystrophy patients, with minimal side effects.

Results of systemic AAV-mini/micro-dystrophin therapy in dystrophic dogs have been mixed. On the one hand, our group and others have demonstrated longterm dystrophin expression, with [194] and without [195] immunosuppression. But, one group of dogs that we studied had delayed growth and pelvic limb muscle atrophy and contractures, seemingly due to an innate immune response (Fig. 8) [195]. Moreover, clear evidence of functional improvement akin to that seen in GRMD dogs with the exon-skipping strategies [186] has not been demonstrated after systemic therapy with AAVmini/micro-dystrophins, giving rise to persistent questions about the ability of mini/micro-dystrophins to sustain myofiber integrity when stressed by larger mammals.

\section{Conclusions}

Duchenne muscular dystrophy (DMD) is a devastating $\mathrm{X}$-linked disease for which ameliorative treatments are desperately needed. As with other inherited conditions, genetically homologous animal models are critical for exploring DMD disease pathogenesis and the efficacy and side effects of potential therapies. Until the $D M D$ gene and dystrophin protein were identified in the 1980s, putative animal models were chosen based on similarities in the pattern of inheritance and common phenotypic features. Golden retriever dogs with an apparent X-linked degenerative myopathy, subsequently termed golden retriever muscular dystrophy (GRMD), were recognized in the 1970s and 1980s and shown to have phenotypic features consistent with those of DMD. These features, including elevated serum enzymes, sarcolemmal defects, and CRDs on EMG, were in keeping with the membrane theory of DMD disease pathogenesis. One of these dogs, Rusty, identified at the University of Georgia in 1981, was the founder for initial colonies at Cornell University and NCSU. Subsequent studies confirmed genetic homology with DMD, and multiple additional colonies were established in the USA and around the world. In a similar time frame, an additional naturally occurring DMD genetic homologue, the

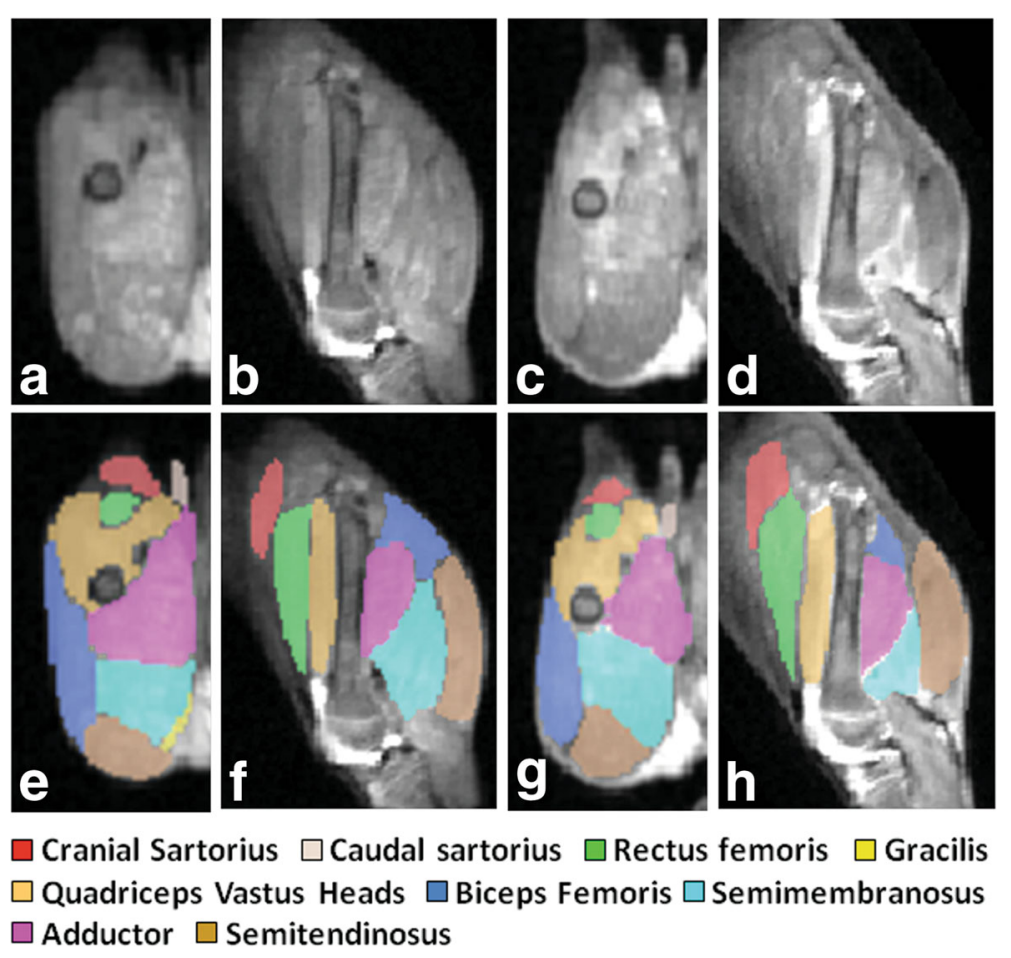

Fig. 8 T2-weighted MR images of GRMD pelvic limb muscles 16 weeks after AAV9-CMV-mini-dystrophin vector intravenous injection. Transverse (left) and sagittal (right) images of two different dogs (dog 1: $\mathbf{a}, \mathbf{b}, \mathbf{e}$, and $\mathbf{f} ; \operatorname{dog} 2: \mathbf{c}, \mathbf{d}, \mathbf{g}$, and $\mathbf{h}$ ) are seen. The images in $\mathbf{e}-\mathbf{h}$ have been segmented and color-coded to outline individual muscles. Signal intense lesions that persisted with fat saturation, most likely representing fluid due to inflammation or edema, are particularly pronounced in the vastus heads of the quadriceps and adductor muscles. From reference [195] 
mdx mouse, was identified and characterized. Extending from these studies in the 1980s, the DMD research community has had these two well-defined genetically homologous animal models to use in tandem for therapy development. However, neither of these models is completely analogous, with the $\mathrm{mdx}$ mouse displaying a mild phenotype and the more severely affected GRMD dog often stabilizing after 6 months of age. Advantages of the $\mathrm{mdx}$ mouse relate to its consistent phenotype and relatively modest expense, allowing multiple variables to be tested through reasonably powered studies. On the other hand, the mouse's small size may limit assessment of scalable variables such as cell migration or drug diffusion. Perhaps even more importantly, preclinical studies in $\mathrm{mdx}$ mice have generally not identified complications, most notably immunologic side effects of gene and cell therapies. These advantages and limitations are essentially reversed for dystrophic dogs. The expense of animal housing and required facilities limits the number of dogs that can be studied. Accordingly, multiple variables, as with the use of immunosuppression, cannot always be tested. Phenotypic variation further reduces the power that can be achieved with GRMD trials. On the other hand, the dog's larger size and outbred nature allows for better modeling of scalable variables such as cell diffusion and the immune response to biologics. A general paradigm has evolved, whereby initial testing is done in mdx mice and, assuming positive results, follow-up studies are completed in dystrophic dogs. As with preclinical studies more generally, findings from these animal models have not consistently translated to DMD patients. Examples of failed translation include pharmacologic approaches, the myoblast transplantation studies of the 1990s, and the current uncertainty surrounding exonskipping strategies. A major factor in this lack of translation has been termed the "two cultures phenomenon," whereby experimental design in animal studies has not consistently mirrored the rigor of human clinical trials, with fundamental tenets such as appropriate powering of outcome parameters and blinding not being sufficiently considered. To address this ongoing problem, certain basic standards should be adopted. Care should be taken in planning the experimental design to ensure that sample sizes are sufficiently powered to detect treatment effects with the outcome parameters used; animals should be randomly assigned to treatment and control groups, and investigators should be blinded to which animals are treated; statistical methods used in data analysis should be carefully considered and reported; endpoints (biomarkers) should largely follow those to be used in future DMD trials and be studied in a natural history setting to allow appropriate powering in advance of the preclinical trial; results should be validated in another laboratory; and, especially for treatments such as cell and gene therapies that carry substantial risk, treatment efficacy and complications should be determined in both the $\mathrm{mdx}$ mouse and GRMD dog. In this last instance, the role of animal models in predicting side effects has often been overlooked or deemphasized. Following on the premise that physicians should first and foremost "do no harm," preclinical studies offer an opportunity to identify potential risks that can be corrected prior to human trials. The GRMD model has played a particularly important role in characterizing complications of pharmacologic intervention and immunologic reactions to cell and gene therapies.

\section{Abbreviations}

6MWT: 6-minute walk test; AAV: Adeno-associated virus; BMD: Becker muscular dystrophy; CK: Creatine kinase; CPK: Creatine phosphokinase; CRDs: Complex repetitive discharges; CXMD: Canine X-linked muscular dystrophy; CXMD: Canine X-linked muscular dystrophy in Japan; DMD: Duchenne muscular dystrophy; EMG: Electromyography; FDA: Food and Drug Administration; GRippets: Cross bred myostatin-heterozygote and GRMD dogs; GRMD: Golden retriever muscular dystrophy; GWAS: Genome wide association study; IND: Investigational new drug; LTBP4: Latent transforming growth factor $\beta$ binding protein 4; MHC: Major histocompatibility complex; mRNA: Messenger ribonucleic acid; NBD: Nemo Binding Domain peptide; NF-KB: Nuclear factor kappa-light-chain-enhancer of activated B cells; RFLPs: Restriction fragment length polymorphisms; SPPI: Phosphoprotein 1 (osteopontin); TT: Tibiotarsal joint; UPS: Ubiquitin-proteasome system

\section{Acknowledgements}

The author acknowledges the roles that dogs with golden retriever muscular dystrophy and many collaborators, graduate students, and technicians have played in cited studies and, in so doing, advanced our understanding of the devastating disease, Duchenne muscular dystrophy, and genetically homologus conditions in dogs.

\section{Funding}

Funding for studies completed in the author's laboratory and cited in this review came from multiple sources and was generally acknowledged in prior papers.

\section{Availability of data and materials}

Data compiled by the author and cited in this paper are generally available for review.

\section{Competing interests}

The author is a paid consultant for Solid Biosciences, which is developing a micro-dystrophin based treatment that is being tested in GRMD dogs.

\section{Consent for publication}

Not applicable.

\section{Ethics approval and consent to participate}

All studies cited by the author in this paper were completed according to principles outlined in the National Research Council Guide for the Care and Use of Laboratory Animals and with approval of the particular university's Institutional Animal Care and Use Committee.

\section{Publisher's Note}

Springer Nature remains neutral with regard to jurisdictional claims in published maps and institutional affiliations.

Received: 4 February 2017 Accepted: 19 April 2017

Published online: 19 May 2017

References

1. Guiraud S, Aartsma-Rus A, Vieira NM, Davies KE, van Ommen GJ, Kunkel LM. The pathogenesis and therapy of muscular dystrophies. Annu Rev Genomics Hum Genet. 2015;16:281-308. 
2. Mendell JR, Shilling C, Leslie ND, Flanigan KM, Al-Dahhak R, Gastier-Foster J, et al. Evidence-based path to newborn screening for Duchenne muscular dystrophy. Ann Neurol. 2012;71:304-13.

3. Multiple authors. Experimental primary myopathies and their relationship to human disease. Ann NY Acad Sci. 1966;138:3-366.

4. Rowland LP. Biochemistry of muscle membranes in Duchenne muscular dystrophy. Muscle Nerve. 1980;3:3-20.

5. Dreyfus JC, Schapii-a G, Schapira I. Biochemical study of muscle in progressive muscular dystrophy. J Clin Invest. 1954;33:794-7.

6. Okinaka S, Kumagai H, Ebashi S, Sugita H, Momoi H, Toyokura Y, et al. Serum creatine phosphokinase. Activity in progressive muscular dystrophy and neuromuscular diseases. Arch Neurol. 1961;4:520-5.

7. Munsat TL, Baloh R, Pearson CM, Fowler Jr W. Serum enzyme alterations in neuromuscular disorders. JAMA. 1973;226:1536-43.

8. Schmalbruch H. Segmental fibre breakdown and defects of the plasmalemma in diseased human muscles. Acta Neuropathol. 1975;33:129-41.

9. Mokri B, Engel AG. Duchenne dystrophy: electron microscopic findings pointing to a basic or early abnormality in the plasma membrane of the muscle fiber. Neurology. 1975;25:1111-20.

10. Pestronk A, Parhad IM, Drachman DB, Price DL. Membrane myopathy: morphological similarities to Duchenne muscular dystrophy. Muscle Nerve. 1982;5:209-14.

11. Carpenter S, Karpati G. Duchenne muscular dystrophy: plasma membrane loss initiates muscle cell necrosis unless it is repaired. Brain. 1979;102:147-61.

12. Buchthal F, Rosenfalck P. Electrophysiologic aspects of myopathy with particular reference to progressive muscular dystrophy. In: Bourne $\mathrm{GH}$, Golarz MN, editors. Muscular dystrophy in man and animals. New York: Hafner Publishing Company; 1963. p. 193-243.

13. Desmedt JE, Borenstein S. Regeneration in Duchenne muscular dystrophy. Electromyographic evidence. Arch Neurol. 1976;33:642-50.

14. Emeryk-Szajewska B, Kopeć J. Electromyographic pattern in Duchenne and Becker muscular dystrophy. Part II. Electromyographic pattern in Becker muscular dystrophy in comparison with Duchenne muscular dystrophy. Electromyogr Clin Neurophysiol. 2008;48:279-84.

15. Ishpekova B, Milanov I, Christova LG, Alexandrov AS. Comparative analysis between Duchenne and Becker types muscular dystrophy. Electromyogr Clin Neurophysiol. 1999;39:315-8.

16. Hehir MK, Logigian EL. Electrodiagnosis of myotonic disorders. Phys Med Rehabil Clin N Am. 2013;24:209-20.

17. AANEM. Glossary of terms in neuromuscular \& electrodiagnostic medicine. Muscle Nerve. 2015;52 Suppl 2:145-203.

18. Fellows LK, Foster BJ, Chalk CH. Clinical significance of complex repetitive discharges: a case-control study. Muscle Nerve. 2003;28:504-7.

19. Georgesco M, Salerno A. Spontaneous electromyographic activity. Practical importance. Neurophysiol Clin. 2000;30:289-305.

20. Partanen JV. Ephaptic transmission from type ii afferents to static $\gamma$ and $\beta$ efferents causes complex repetitive discharge: an hypothesis. Muscle Nerve. 2016;53:508-12.

21. Franke C, Hatt H, laizzo PA, Lehmann-Horn F. Characteristics of Na+ channels and $\mathrm{Cl}$-conductance in resealed muscle fibre segments from patients with myotonic dystrophy. J Physiol. 1990;425:391-405.

22. Hirn C, Shapovalov G, Petermann O, Roulet E, Ruegg UT. Nav1.4 deregulation in dystrophic skeletal muscle leads to Na+ overload and enhanced cell death. J Gen Physiol. 2008;132:199-208.

23. Han JJ, Carter GT, Ra JJ, Abresch RT, Chamberlain JS, Robinson LR Electromyographic studies in mdx and wild-type C57 mice. Muscle Nerve. 2006;33:208-14

24. Carter GT, Longley KJ, Entrikin RK. Electromyographic and nerve conduction studies in the mdx mouse. Am J Phys Med Rehabil. 1992;71:2-5.

25. Walton JN. On the inheritance of muscular dystrophy. Ann Hum Genet. 1955;20:1-13.

26. Milhorat AT, Wolff HG. Studies in diseases of muscle: XII. Heredity of progressive muscular dystrophy; relationship between age at onset of symptoms and clinical course. Arch Neurol Psychiatry. 1943;49:641-54.

27. Gardner-Medwin D, Johnston HM. Severe muscular dystrophy in girls. J Neurol Sci. 1984;64:79-87.

28. Soltanzadeh P, Friez MJ, Dunn D, von Niederhausern A, Gurvich OL, Swoboda $\mathrm{KJ}$, et al. Clinical and genetic characterization of manifesting carriers of DMD mutations. Neuromuscul Disord. 2010;20:499-504.

29. Boyd Y, Buckle $V$, Holt S, Munro E, Hunter D, Craig I. Muscular dystrophy in girls with X; autosome translocations. J Med Genet. 1986;23:484-90.
30. Davies KE, Pearson PL, Harper PS, Murray JM, O'Brien T, Sarfarazi M, et al. Linkage analysis of two cloned DNA sequences flanking the Duchenne muscular dystrophy locus on the short arm of the human $\mathrm{X}$ chromosome. Nucleic Acids Res. 1983:11:2303-12.

31. Kingston HM, Thomas NS, Pearson PL, Sarfarazi M, Harper PS. Genetic linkage between Becker muscular dystrophy and a polymorphic DNA sequence on the short arm of the X chromosome. J Med Genet. 1983;20:255-8.

32. Kunkel LM, Monaco AP, Middlesworth W, Ochs HD, Latt SA. Specific cloning of DNA fragments absent from the DNA of a male patient with an $\mathrm{X}$ chromosome deletion. Proc Natl Acad Sci U S A. 1985;82:4778-82.

33. Francke $U$, Ochs HD, de Martinville $B$, Giacalone J, Lindgren $V$, Distèche $C$, et al. Minor Xp21 chromosome deletion in a male associated with expression of Duchenne muscular dystrophy, chronic granulomatous disease, retinitis pigmentosa, and McLeod syndrome. Am J Hum Genet. 1985;37:250-67.

34. Kunkel LM, Hejtmancik JF, Caskey CT, Speer A, Monaco AP, Middlesworth W, et al. Analysis of deletions in DNA from patients with Becker and Duchenne muscular dystrophy. Nature. 1986;322:73-7.

35. Koenig M, Hoffman EP, Bertelson CJ, Monaco AP, Feener C, Kunkel LM. Complete cloning of the Duchenne muscular dystrophy (DMD) cDNA and preliminary genomic organization of the DMD gene in normal and affected individuals. Cell. 1987;50:509-17.

36. Hoffman EP, Brown Jr RH, Kunkel LM. Dystrophin: the protein product of the Duchenne muscular dystrophy locus. Cell. 1987;51:919-28.

37. Monaco AP, Bertelson CJ, Liechti-Gallati S, Moser H, Kunkel LM. An explanation for the phenotypic differences between patients bearing partial deletions of the DMD locus. Genomics. 1988;2:90-5.

38. Prior TW, Bridgeman SJ. Experience and strategy for the molecular testing of Duchenne muscular dystrophy. J Mol Diagn. 2005;7:317-26.

39. Traverso M, Malnati M, Minetti C, Regis S, Tedeschi S, Pedemonte M, et al. Multiplex real-time PCR for detection of deletions and duplications in dystrophin gene. Biochem Biophys Res Commun. 2006;339:145-50.

40. Flanigan KM, Dunn DM, von Niederhausern A, Soltanzadeh P, Gappmaier E, Howard MT, et al. Mutational spectrum of DMD mutations in dystrophinopathy patients: application of modern diagnostic techniques to a large cohort. Hum Mutat. 2009;30:1657-66.

41. Flanigan KM. Duchenne and Becker muscular dystrophies. Neurol Clin. 2014; 32:671-88.

42. Miskew Nichols B, Aoki Y, Kuraoka M, Lee JJ, Takeda S, Yokota T. Multi-exon skipping using cocktail antisense oligonucleotides in the canine X-linked muscular dystrophy. J Vis Exp. 2016;24:111.

43. Campbell KP, Kahl SD. Association of dystrophin and an integral membrane glycoprotein. Nature. 1989;338:259-62.

44. Cohn RD, Campbell KP. Molecular basis of muscular dystrophies. Muscle Nerve. 2000;23:1456-71.

45. Ervasti JM. Dystrophin, its interactions with other proteins, and implications for muscular dystrophy. Biochim Biophys Acta. 2007;1772:108-17.

46. Witkowski JA. Review article: dystrophin-related muscular dystrophies. J Child Neurol. 1989;4:251-71.

47. Dubowitz $\bigvee$. Review article: the Duchenne dystrophy story: from phenotype to gene and potential treatment. J Child Neurol. 1989:4:240-50.

48. Lewis J. Between the lines: a message of hope. J Child Neurol. 1989;4:272-3.

49. Shieh PB. Duchenne muscular dystrophy: clinical trials and emerging tribulations. Curr Opin Neurol. 2015:28:542-6.

50. Straub V, Balabanov P, Bushby K, Ensini M, Goemans N, De Luca A, et al. Stakeholder cooperation to overcome challenges in orphan medicine development: the example of Duchenne muscular dystrophy. Lancet Neurol. 2016;15:882-90

51. Arrowsmith J. Trial watch: Phase II failures: 2008-2010. Nat Rev Drug Discov. 2011;10:328-9.

52. Arrowsmith J, Miller P. Trial watch: phase II and phase III attrition rates 2011-2012. Nat Rev Drug Discov. 2013;12:569.

53. Carlisle B, Kimmelman J, Ramsay T, MacKinnon N. Unsuccessful trial accrual and human subjects protections: an empirical analysis of recently closed trials. Clin Trials. 2015;12:77-83.

54. Milne CP. Prospects for rapid advances in the development of new medicines for special medical needs. Clin Pharmacol Ther. 2014;95:98-109.

55. Bushby K, Finkel R, Wong B, Barohn R, Campbell C, Comi GP, et al. Ataluren treatment of patients with nonsense mutation dystrophinopathy. Muscle Nerve. 2014;50:477-87.

56. Haas M, Vlcek V, Balabanov P, Salmonson T, Bakchine S, Markey G, et al. European Medicines Agency review of ataluren for the treatment of ambulant 
patients aged 5 years and older with Duchenne muscular dystrophy resulting from a nonsense mutation in the dystrophin gene. Neuromuscul Disord. 2015;25:5-13.

57. Witting N, Kruuse C, Nyhuus B, Prahm KP, Citirak G, Lundgaard SJ, et al. Effect of sildenafil on skeletal and cardiac muscle in Becker muscular dystrophy. Ann Neurol. 2014;76:550-7.

58. Leung DG, Herzka DA, Thompson WR, He B, Bibat G, Tennekoon G, et al. Sildenafil does not improve cardiomyopathy in Duchenne/Becker muscular dystrophy. Ann Neurol. 2014;76:541-9.

59. Editorial. Railroading at the FDA. Nature Biotech. 2016;34:1078.

60. Syed YY. Eteplirsen: first global approval. Drugs. 2016;2 [Epub ahead of print].

61. Jacobs AC, Hatfield KP. History of chronic toxicity and animal carcinogenicity studies for pharmaceuticals. Vet Pathol. 2013;50:324-33.

62. Lehman AJ, Patterson WI, Davidow B, Hagan EC, Woodard G, Laug EP, et al. Procedures for the appraisal of the toxicity of chemicals in foods, drugs and cosmetics. Food Drug Cosmet Law J. 1955;10:679-748.

63. Bailey GP, Mariën D. The value of juvenile animal studies "What have we learned from preclinical juvenile toxicity studies? "I". Birth Defects Res B Dev Reprod Toxicol. 2011;92:273-91.

64. Bailey AM, Mendicino M, Au P. An FDA perspective on preclinical development of cell-based regenerative medicine products. Nat Biotechnol. 2014;32:721-3.

65. Bailey AM, Arcidiacono J, Benton KA, Taraporewala Z, Winitsky S. United States food and drug administration regulation of gene and cell therapies. Adv Exp Med Biol. 2015;871:1-29.

66. National Research Council. Models for biomedical research. A new perspective. Washington, DC: The National Academy Press; 1985.

67. Bulfield G, Siller WG, Wight PAL, Moore KJ. X chromosome-linked muscular dystrophy (mdx) in the mouse. Proc Natl Acad Sci U S A. 1984;81:1189-92.

68. Manning J, O'Malley D. What has the mdx mouse model of Duchenne muscular dystrophy contributed to our understanding of this disease? J Muscle Res Cell Motil. 2015;36:155-67

69. Sicinski P, Geng Y, Ryder-Cook AS, Barnard EA, Darlison MG, Barnard PJ. The molecular basis of muscular dystrophy in the mdx mouse: a point mutation. Science. 1989;244:1578-80.

70. Brinkmeyer-Langford C, Kornegay JN. Comparative genomics of X-linked muscular dystrophies: the golden retriever model. Curr Genomics. 2013;14:330-42.

71. Carpenter JL, Hoffman EP, Romanul FC, Kunkel LM, Rosales RK, Ma NS, et al. Feline muscular dystrophy with dystrophin deficiency. Am J Pathol. 1989;135:909-19.

72. Gaschen FP, Hoffman EP, Gorospe JR, Uhl EW, Senior DF, Cardinet 3rd GH, et al. Dystrophin deficiency causes lethal muscle hypertrophy in cats. J Neurol Sci. 1992;110:149-59.

73. Selsby JT, Ross JW, Nonneman D, Hollinger K. Porcine models of muscular dystrophy. ILAR J. 2015;56:116-26.

74. Gaschen F, Gaschen L, Seiler G, Welle M, Jaunin VB, Jmaa DG, et al. Lethal peracute rhabdomyolysis associated with stress and general anesthesia in three dystrophin-deficient cats. Vet Pathol. 1998;35:117-23.

75. Kornegay JN, Childers MK. Canine inherited dystrophinopathies and centronuclear myopathies. In: Childers MK, editor. Regenerative medicine for degenerative muscle diseases. Series title: stem cell biology and regenerative medicine. New York: Humana Press; 2016. p. 309-29.

76. Larcher T, Lafoux A, Tesson L, Remy S, Thepenier V, François V. Characterization of dystrophin deficient rats: a new model for Duchenne muscular dystrophy. PLoS One. 2014;9(10):e110371.

77. Kornegay JN, Spurney CF, Nghiem PP, Brinkmeyer-Langford CL, Hoffman EP, Nagaraju K. Pharmacologic management of Duchenne muscular dystrophy: target identification and preclinical trials. ILAR J. 2014;55:119-49.

78. Partridge TA. The mdx mouse model as a surrogate for Duchenne muscular dystrophy. FEBS J. 2013;280:4177-86.

79. Ergorul C, Levin LA. Solving the lost in translation problem: improving the effectiveness of translational research. Curr Opin Pharmacol. 2013;13:108-14.

80. Landis SC, Amara SG, Asadullah K, Austin CP, Blumenstein R, Bradley EW, et al. A call for transparent reporting to optimize the predictive value of preclinical research. Nature. 2012;490:187-91.

81. Willmann R, Luca A, Nagaraju K, Rüegg MA. Best practices and standard protocols as a tool to enhance translation for neuromuscular disorders. J Neuromuscul Dis. 2015;14:113-7.

82. Cardinet GH, Holliday TA. Neuromuscular diseases of domestic animals: a summary of muscle biopsies from 159 cases. Ann NY Acad Sci. 1979; 317:290-313.

83. Valentine BA, Cooper BJ, Dietze AE, Noden DM. Canine congenital diaphragmatic hernia. J Vet Intern Med. 1988;2:109-12.
84. Kornegay JN. Golden retriever myopathy. In: Kirk RW, editor. Current veterinary therapy IX. Philadelphia: WB Saunders Co; 1986. p. 792-4.

85. Kornegay JN, Tuler SM, Miller DM, Levesque DC. Muscular dystrophy in a litter of golden retriever dogs. Muscle Nerve. 1988;11:1056-64.

86. Valentine BA, Cooper BJ, de Lahunta A, O'Quinn R, Blue JT. Canine X-linked muscular dystrophy. An animal model of Duchenne muscular dystrophy: clinical studies. J Neurol Sci. 1988;88:69-81.

87. Valentine BA, Cooper BJ, Cummings JF, de Lahunta A. Canine X-linked muscular dystrophy: morphologic lesions. J Neurol Sci. 1990;97:1-23.

88. Meier H. Myopathies in the dog. Cornell Vet. 1958;48:313-30.

89. Keijzer R, Puri P. Congenital diaphragmatic hernia. Semin Pediatr Surg. 2010; 19:180-5.

90. Inanlou MR, Kablar B. Abnormal development of the diaphragm in mdx: MyoD-/-(9th) embryos leads to pulmonary hypoplasia. Int J Dev Biol. 2003; 47:363-71.

91. deLahunta A. Veterinary neuroanatomy and clinical neurology. Philadelphia: WB Saunders Co; 1977. p. 84-5.

92. Wentink GH, Meijer AE, van der Linde-Sipman JS, Hendriks HJ. Myopathy in an irish terrier with a metabolic defect of the isolated mitochondria. Zentralbl Veterinarmed A. 1974;21:62-74.

93. Valentine BA, Cooper BJ, Cummings JF, deLahunta A. Progressive muscular dystrophy in a golden retriever dog: light microscope and ultrastructural features at 4 and 8 months. Acta Neuropathol. 1986;71:301-10.

94. Cooper BJ, Winand NJ, Stedman H, Valentine BA, Hoffman EP, Kunkel LM, et al. The homologue of the Duchenne locus is defective in X-linked muscular dystrophy of dogs. Nature. 1988;334:154-6.

95. Cooper BJ, Valentine BA, Wilson S, Patterson DF, Concannon PW. Canine muscular dystrophy: confirmation of X-linked inheritance. J Hered. 1988;79:405-8.

96. Sharp NJ, Kornegay JN, Van Camp SD, Herbstreith MH, Secore SL, Kettle S, et al. An error in dystrophin mRNA processing in golden retriever muscular dystrophy, an animal homologue of Duchenne muscular dystrophy. Genomics. 1992;13:115-21.

97. Kornegay JN, Bogan JR, Bogan DJ, Childers MK, Li J, Nghiem P, et al. Canine models of Duchenne muscular dystrophy and their use in therapeutic strategies. Mamm Genome. 2012;23:85-108.

98. Smith BF, Yue Y, Woods PR, Kornegay JN, Shin JH, Williams RR, et al. An intronic LINE-1 element insertion in the dystrophin gene aborts dystrophin expression and results in Duchenne-like muscular dystrophy in the corgi breed. Lab Invest. 2011;91:216-31.

99. Atencia-Fernandez S, Shiel RE, Mooney CT, Nolan CM. Muscular dystrophy in the Japanese Spitz: an inversion disrupts the DMD and RPGR genes. Anim Genet. 2015;46:175-84.

100. Jenkins CA, Forman OP. Identification of a novel frameshift mutation in the DMD gene as the cause of muscular dystrophy in a Norfolk terrier dog. Canine Genet Epidemiol. 2015;2:7.

101. Schatzberg SJ, Olby NJ, Breen M, Anderson LV, Langford CF, Dickens HF, et al. Molecular analysis of a spontaneous dystrophin "knockout" dog. Neuromuscul Disord. 1999;9:289-95.

102. VanBelzen DJ, Malik AS, Henthorn PS, Kornegay JN, Stedman HH. Mechanism of deletion removing all dystrophin exons in canine model for DMD implicates concerted evolution of X-chromosome pseudogenes. Mol Ther Methods Clin Dev. 2016;24:62-71.

103. Walmsley GL, Arechavala-Gomeza V, Fernandez-Fuente M, Burke MM, Nagel $\mathrm{N}$, Holder A, et al. A duchenne muscular dystrophy gene hot spot mutation in dystrophin-deficient cavalier king charles spaniels is amenable to exon 51 skipping. PLoS One. 2010;5(1):e8647.

104. Nghiem PP, Bello L, Balog C, Mata-López S, Bettis A, Barnett H, et al. Whole genome sequencing reveals a 7 base-pair deletion in DMD exon 42 in a dog with muscular dystrophy. Mamm Genome. 2016.

105. Winand N, Pradham D, Cooper B. Molecular characterization of severe Duchenne-type muscular dystrophy in a family of Rottweiler dogs. Tucson: Molecular Mechanisms of Neuromuscular Disease, Muscular Dystrophy Association; 1994.

106. Schatzberg SJ, Anderson LV, Wilton SD, Kornegay JN, Mann CJ, Solomon $\mathrm{GG}$, et al. Alternative dystrophin gene transcripts in golden retriever muscular dystrophy. Muscle Nerve. 1998;21:991-8.

107. Nicholson LV. The "rescue" of dystrophin synthesis in boys with Duchenne muscular dystrophy. Neuromuscul Disord. 1993;3:525-31.

108. Nicholson LV, Johnson MA, Bushby KM, Gardner-Medwin D. Functional significance of dystrophin positive fibres in Duchenne muscular dystrophy. Arch Dis Child. 1993;68:632-6. 
109. Arechavala-Gomeza V, Kinali M, Feng L, Guglieri M, Edge G, Main M, et al. Revertant fibres and dystrophin traces in Duchenne muscular dystrophy: implication for clinical trials. Neuromuscul Disord. 2010;20:295-301.

110. Baroncelli AB, Abellonio F, Pagano TB, Esposito I, Peirone B, Papparella S, et al. Muscular dystrophy in a dog resembling human becker muscular dystrophy. J Comp Pathol. 2014;150:429-33.

111. Vieira NM, Guo LT, Estrela E, Kunkel LM, Zatz M, Shelton GD. Muscular dystrophy in a family of Labrador Retrievers with no muscle dystrophin and a mild phenotype. Neuromuscul Disord. 2015;25:363-70.

112. Olby NJ, Sharp NJ, Nghiem PE, Keene BW, DeFrancesco TC, Sidley JA, et al. Clinical progression of X-linked muscular dystrophy in two German Shorthaired Pointers. J Am Vet Med Assoc. 2011;238:207-12.

113. Vieira NM, Elvers I, Alexander MS, Moreira YB, Eran A, Gomes JP, et al. Jagged 1 rescues the Duchenne muscular dystrophy phenotype. Cell. 2015;163:1204-13.

114. Brinkmeyer-Langford C, Balog-Alvarez C, Cai JJ, Davis BW, Kornegay JN. Genomewide association study to identify potential genetic modifiers in a canine model for Duchenne muscular dystrophy. BMC Genomics. 2016;17:665.

115. Shimatsu Y, Katagiri K, Furuta T, Nakura M, Tanioka Y, Yuasa K, et al. Canine X-linked muscular dystrophy in Japan (CXMDJ). Exp Anim. 2003;52:93-7.

116. Yokota T, Lu QL, Partridge T, Kobayashi M, Nakamura A, Takeda S, et al. Efficacy of systemic morpholino exon-skipping in Duchenne dystrophy dogs. Ann Neurol. 2009;65:667-76

117. Patronek GJ, Waters DJ, Glickman LT. Comparative longevity of pet dogs and humans: implications for gerontology research. J Gerontol A Biol Sci Med Sci. 1997;52:B171-8.

118. Brooke MH, Fenichel GM, Griggs RC, Mendell JR, Moxley R, Miller JP, et al. Clinical investigation in Duchenne dystrophy: 2. Determination of the "power" of therapeutic trials based on the natural history. Muscle Nerve. 1983;6:91-103.

119. McDonald CM, Abresch RT, Carter GT, Fowler Jr WM, Johnson ER, Kilmer DD et al. Profiles of neuromuscular diseases. Duchenne muscular dystrophy. Am J Phys Med Rehabil. 1995;74 Suppl 5:70-92.

120. Kornegay JN, Bogan JR, Bogan DJ, Childers MK, Grange RW. Golden retriever muscular dystrophy (GRMD): developing and maintaining a colony and physiological functional measurements. Methods Mol Biol. 2011;709:105-23.

121. Nigro G. Importance of cardiological studies in the muscular dystrophies. Cardiomyology. 1983;2:209-19.

122. Nigro G, Comi LI, Politano L, Bain RJI. The incidence and evolution of cardiomyopathy in Duchenne muscular dystrophy. Int J Cardiol. 1990;26:271-7.

123. Markham LW, Michelfelder EC, Border WL, Khoury PR, Spicer RL, Wong BL, et al. Abnormalities of diastolic function precede dilated cardiomyopathy associated with Duchenne muscular dystrophy. J Am Soc Echo. 2006;19:865-71.

124. Bushby KMD, Hill A, Steele JG. Failure of early diagnosis in symptomatic Duchenne muscular dystrophy. Lancet. 1999;353:557-8.

125. Nicholson LV, Johnson MA, Bushby KM, Gardner-Medwin D, Curtis A, Ginjaar IB, et al. Integrated study of 100 patients with Xp21 linked muscular dystrophy using clinical, genetic, immunocytochemical, and histopathological data. Part 1. Trends across the clinical groups. J Med Genet. 1993;30:728-37.

126. Khirani S, Ramirez A, Aubertin G, Boulé M, Chemouny C, Forin V, et al. Respiratory muscle decline in Duchenne muscular dystrophy. Pediatr Pulmonol. 2014;49:473-81.

127. Fine DM, Shin JH, Yue Y, Volkmann D, Leach SB, Smith BF, et al. Age-matched comparison reveals early electrocardiography and echocardiography changes in dystrophin-deficient dogs. Neuromuscul Disord. 2011;21:453-61.

128. Moise NS, Valentine BA, Brown CA, Erb HN, Beck KA, Cooper BJ, et al. Duchenne's cardiomyopathy in a canine model: electrocardiographic and echocardiographic studies. J Am Coll Cardiol. 1991;17:812-20.

129. Nakamura A, Kobayashi M, Kuraoka M, Yuasa K, Yugeta N, Okada T, et al. Initial pulmonary respiration causes massive diaphragm damage and hyperCKemia in Duchenne muscular dystrophy dog. Sci Rep. 2013;3:2183.

130. Kornegay JN, Bogan DJ, Bogan JR, Childers MK, Cundiff DD, Petroski GF, et al. Contraction force generated by tibiotarsal joint flexion and extension in dogs with golden retriever muscular dystrophy. J Neurol Sci. 1999;166:115-21.

131. Barthélémy I, Pinto-Mariz F, Yada E, Desquilbet L, Savino W, Silva-Barbosa SD, et al. Predictive markers of clinical outcome in the GRMD dog model of Duchenne muscular dystrophy. Dis Model Mech. 2014;7:1253-61.

132. Bello L, Kesari A, Gordish-Dressman H, Cnaan A, Morgenroth LP, Punetha J, et al. Genetic modifiers of ambulation in the cooperative international Neuromuscular research group Duchenne natural history study. Ann Neurol. 2015;77:684-96.

133. Liu JM, Okamura CS, Bogan DJ, Bogan JR, Childers MK, Kornegay JN. Effects of prednisone in canine muscular dystrophy. Muscle Nerve. 2004; 30:767-73.
134. Acosta AR, Van Wie E, Stoughton WB, Bettis AK, Barnett HH, LaBrie NR, et al. Use of the six-minute walk test to characterize golden retriever muscular dystrophy. Neuromuscul Disord. 2016;26:865-72.

135. Kornegay JN, Peterson JM, Bogan DJ, Kline W, Bogan JR, Dow JL, et al. NBD delivery improves the disease phenotype of the golden retriever model of Duchenne muscular dystrophy. Skelet Muscle. 2014;4:18.

136. Edwards RHT, Jones DA, Newham DJ, Chapman SJ. Role of mechanical damage in the pathogenesis of proximal myopathy in man. Lancet. 1984; 1(8376):548-52.

137. Barthélémy I, Uriarte A, Drougard C, Unterfinger $Y$, Thibaud JL, Blot S. Effects of an immunosuppressive treatment in the GRMD dog model of Duchenne muscular dystrophy. PLoS One. 2012;7:e48478.

138. Galindo CL, Soslow JH, Brinkmeyer-Langford CL, Gupte M, Smith HM, Sengsayadeth $\mathrm{S}$, et al. Translating golden retriever muscular dystrophy microarray findings to novel biomarkers for cardiac/skeletal muscle function in Duchenne muscular dystrophy. Pediatr Res. 2016;79:629-36.

139. Nghiem PP, Hoffman EP, Mittal P, Brown KJ, Schatzberg SJ, Ghimbovschi S, et al. Sparing of the dystrophin-deficient cranial sartorius muscle is associated with classical and novel hypertrophy pathways in GRMD dogs. Am J Pathol. 2013;183:1411-24.

140. Gloss D, Moxley 3rd RT, Ashwal S, Oskoui M. Practice guideline update summary: corticosteroid treatment of Duchenne muscular dystrophy: Report of the Guideline Development subcommittee of the American Academy of Neurology. Neurology. 2016;86:465-72.

141. Matthews E, Brassington R, Kuntzer T, Jichi F, Manzur AY. Corticosteroids for the treatment of Duchenne muscular dystrophy. Cochrane Database Syst Rev. 2016;5:CD003725.

142. Connolly AM, Schierbecker J, Renna R, Florence J. High dose weekly oral prednisone improves strength in boys with Duchenne muscular dystrophy. Neuromuscul Disord. 2001;12:917-25.

143. Reagan-Shaw S, Nihal M, Ahmad N. Dose translation from animal to human studies revisited. FASEB J. 2008;22:659-61.

144. Auphan N, DiDonato JA, Rosette C, Helmberg A, Karin M. Immunosuppression by glucocorticoids: inhibition of NF-kappa B activity through induction of I kappa B synthesis. Science. 1995;270:286-90.

145. Monici MC, Aguennouz M, Mazzeo A, Messina C, Vita G. Activation of nuclear factor-kappaB in inflammatory myopathies and Duchenne muscular dystrophy. Neurology. 2003;60:993-7.

146. Gazzerro E, Assereto S, Bonetto A, Sotgia F, Scarfi S, Pistorio A, et al. Therapeutic potential of proteasome inhibition in Duchenne and Becker muscular dystrophies. Am J Pathol. 2010;176:1863-77.

147. Briguet A, Erb M, Courdier-Fruh I, Barzaghi P, Santos G, Herzner H, et al. Effect of calpain and proteasome inhibition on Ca2+-dependent proteolysis and muscle histopathology in the mdx mouse. FASEB J. 2008;22:4190-200.

148. Wadosky KM, Li L, Rodríguez JE, Min J, Bogan D, Gonzalez J, et al. Regulation of the calpain and ubiquitin proteasome systems in a canine model of Duchenne muscular dystrophy. Muscle Nerve. 2011;44:553-62.

149. Childers MK, Bogan JR, Bogan DJ, Greiner H, Holder M, Grange RW, et al. Chronic administration of a leupeptin-derived calpain inhibitor fails to ameliorate severe muscle pathology in a canine model of duchenne muscular dystrophy. Front Pharmacol. 2012;2:89.

150. McPherron AC, Lawler AM, Lee S-J. Regulation of skeletal muscle mass in mice by a new TGF- $\beta$ superfamily member. Nature. 1997;387:83-90.

151. Lee S-J. Regulation of muscle mass by myostatin. Annu Rev Cell Dev Biol. 2004;20:61-86

152. Wagner KR, McPherron AC, Winik N, Lee SJ. Loss of myostatin attenuates severity of muscular dystrophy in mdx mice. Ann Neurol. 2002;52:832-6.

153. Wagner KR, Liu X, Chang $X$, Allen RE. Muscle regeneration in the prolonged absence of myostatin. Proc Natl Acad Sci U S A. 2005;102:2519-24.

154. Qiao C, Li J, Zheng H, Bogan J, Li J, Yuan Z, et al. Hydrodynamic limb vein injection of adeno-associated virus serotype 8 vector carrying canine myostatin propeptide gene into normal dogs enhances muscle growth. Hum Gene Ther. 2009:20:1-10.

155. Bish LT, Sleeper MM, Forbes SC, Morine KJ, Reynolds C, Singletary GE, et al. Long-term systemic myostatin inhibition via liver-targeted gene transfer in golden retriever muscular dystrophy. Hum Gene Ther. 2011;22:1499-509.

156. Chen Y-W, Nagaraju K, Bakay M, McIntyre O, Rawat R, Shi R, et al. Early onset of inflammation and later involvement of TGF $\beta$ in Duchenne muscular dystrophy. Neurology. 2005:65:826-34.

157. Tseng BS, Zhao P, Pattison JS, Gordon SE, Granchelli JA, Madsen RW, et al. Regenerated mdx mouse skeletal muscle shows differential mRNA expression. J Appl Physiol. 2002;93:537-45. 
158. Kornegay JN, Bogan DJ, Bogan JR, Dow JL, Wang J, Fan Z, et al. Dystrophindeficient dogs with reduced myostatin have unequal muscle growth and greater joint contractures. Skelet Muscle. 2016;6:14.

159. Partridge TA, Morgan JE, Coulton GR, Hoffman EP, Kunkel LM. Conversion of mdx myofibres from dystrophin-negative to -positive by injection of normal myoblasts. Nature. 1989;337:176-9.

160. Tremblay JP, Malouin F, Roy R, Huard J, Bouchard JP, Satoh A, et al. Results of a triple blind clinical study of myoblast transplantations without immunosuppressive treatment in young boys with Duchenne muscular dystrophy. Cell Transplant. 1993;2:99-112.

161. Miller RG, Sharma KR, Pavlath GK, Gussoni E, Mynhier M, Yu P, et al. Myoblast transplantation in Duchenne muscular dystrophy: the San Francisco study. Muscle Nerve. 1997;20:469-78

162. Partridge T. Myoblast transplantation. Neuromuscul Disord. 2002;12 Suppl 1:3-6.

163. Smythe GM, Hodgetts SI, Grounds MD. Problems and solutions in myoblast transfer therapy. J Cell Mol Med. 2001;5:33-47.

164. Skuk D, Paradis M, Goulet M, Tremblay JP. Ischemic central necrosis in pockets of transplanted myoblasts in nonhuman primates: implications for cell-transplantation strategies. Transplantation. 2007:84:1307-15.

165. Prattis SM, Horton SB, Van Camp SD, Kornegay JN. Immunohistochemical detection of neural cell adhesion molecule and laminin in X-linked dystrophic dogs and mdx mice. J Comp Pathol. 1994;110:253-66.

166. Kornegay JN, Prattis SM, Bogan DJ, Sharp NJH, Bartlett RJ, Alameddine HS, et al. Results of myoblast transplantation in a canine model of muscle injury. In: Kakulas BA, Mc HJ, Roses AD, editors. Duchenne muscular dystrophy. Animal models and genetic manipulation. San Diego: Raven; 1992. p. 203-12.

167. Gussoni E, Soneoka Y, Strickland CD, Buzney EA, Khan MK, Flint AF, et al. Dystrophin expression in the $\mathrm{mdx}$ mouse restored by stem cell transplantation. Nature. 1999:401:390-4.

168. Gussoni E, Bennett RR, Muskiewicz KR, Meyerrose T, Nolta JA, Gilgoff I, et al. Long-term persistence of donor nuclei in a Duchenne muscular dystrophy patient receiving bone marrow transplantation. J Clin Invest. 2002;110:807-14.

169. Ferrari G, Stornaiuolo A, Mavilio F. Failure to correct murine muscular dystrophy. Nature. 2001;411:1014-5.

170. Storb R, Thomas ED. Graft-versus-host disease in dog and man: the Seattle experience. Immunol Rev. 1985;88:215-38.

171. Dell'Agnola C, Wang Z, Storb R, Tapscott SJ, Kuhr CS, Hauschka SD, et al. Hematopoietic stem cell transplantation does not restore dystrophin expression in Duchenne muscular dystrophy dogs. Blood. 2004;104:4311-8.

172. Loperfido M, Jarmin S, Dastidar S, Di Matteo M, Perini I, Moore M, et al. piggyBac transposons expressing full-length human dystrophin enable genetic correction of dystrophic mesoangioblasts. Nucleic Acids Res. 2016; 44:744-60.

173. Pelatti MV, Gomes JP, Vieira NM, Cangussu E, Landini V, Andrade T, et al. Transplantation of human adipose mesenchymal stem cells in nonimmunosuppressed GRMD dogs is a safe procedure. Stem Cell Rev. 2016;12:448-53.

174. Robriquet F, Babarit C, Larcher T, Dubreil L, Ledevin M, Goubin H, et al. Identification in GRMD dog muscle of critical miRNAs involved in pathophysiology and effects associated with MuStem cell transplantation. BMC Musculoskelet Disord. 2016;17:209.

175. Skuk D, Tremblay JP. Cell therapy in muscular dystrophies: many promises in mice and dogs, few facts in patients. Expert Opin Biol Ther. 2015;15:1307-19.

176. Boulanger A, Asselin I, Roy R, Tremblay JP. Role of non-major histocompatibility complex antigens in the rejection of transplanted myoblasts. Transplantation. 1997;63:893-9.

177. Sampaolesi M, Blot S, D'Antona G, Granger N, Tonlorenzi R, Innocenzi A, et al. Mesoangioblast stem cells ameliorate muscle function in dystrophic dogs. Nature. 2006;444:574-9.

178. Davies KE, Grounds MD. Treating muscular dystrophy with stem cells? Cell. 2006;127:1304-6.

179. Rouger K, Larcher T, Dubreil L, Deschamps JY, Le Guiner C, Jouvion G, et al. Systemic delivery of allogenic muscle stem (MuStem) cells Induces longterm muscle repair and clinical efficacy in Duchenne muscular dystrophy dogs. Am J Pathol. 2011;179:2501-18.

180. Zucconi E, Vieira NM, Bueno Jr CR, Secco M, Jazedje T, CostaValadares M, et al. Preclinical studies with umbilical cord mesenchymal stromal cells in different animal models for muscular dystrophy. J Biomed Biotechnol. 2011; 2011:715251.
181. Vieira NM, Valadares M, Zucconi E, Secco M, Bueno Jr CR, et al. Human adipose-derived mesenchymal stromal cells injected systemically into GRMD dogs without immunosuppression are able to reach the host muscle and express human dystrophin. Cell Transplant. 2012;21:1407-17.

182. Sitzia C, Farini A, Jardim L, Razini P, Belicchi M, Cassinelli L, et al. Adaptive immune response impairs the efficacy of autologous transplantation of engineered stem cells in dystrophic dogs. Mol Ther. 2016;24(11):1949-64.

183. Yokota T, Nakamura A, Nagata T, Saito T, Kobayashi M, Aoki Y, et al. Extensive and prolonged restoration of dystrophin expression with vivomorpholino-mediated multiple exon skipping in dystrophic dogs. Nucleic Acid Ther. 2012;22:306-15.

184. Vulin A, Barthélémy I, Goyenvalle A, Thibaud JL, Beley C, Griffith G, et al. Muscle function recovery in golden retriever muscular dystrophy after AAV1-U7 exon skipping. Mol Ther. 2012;20:2120-33.

185. Bish LT, Sleeper MM, Forbes SC, Wang B, Reynolds C, Singletary GE, et al. Long-term restoration of cardiac dystrophin expression in golden retriever muscular dystrophy following rAAV6-mediated exon skipping. Mol Ther. 2012;20:580-9.

186. Le Guiner C, Montus M, Servais L, Cherel Y, Francois $V$, Thibaud JL, et al. Forelimb treatment in a large cohort of dystrophic dogs supports delivery of a recombinant AAV for exon skipping in Duchenne patients. Mol Ther. 2014:22:1923-35.

187. Wang Z, Allen JM, Riddell SR, Gregorevic P, Storb R, Tapscott SJ, et al Immunity to adeno-associated virus-mediated gene transfer in a random-bred canine model of Duchenne muscular dystrophy. Hum Gene Ther. 2007;18:18-26.

188. Yuasa K, Yoshimura M, Urasawa N, Ohshima S, Howell JM, Nakamura A, et al. Injection of a recombinant AAV serotype 2 into canine skeletal muscles evokes strong immune responses against transgene products. Gene Ther. 2007;14:1249-60.

189. Wang Z, Kuhr CS, Allen JM, Blankenship M, Gregorevic P, Chamberlain JS, et al. Sustained AAV-mediated dystrophin expression in a canine model of Duchenne muscular dystrophy with a brief course of immunosuppression. Mol Ther. 2007:15:1160-6.

190. Koo T, Okada T, Athanasopoulos T, Foster H, Takeda S, Dickson G. Longterm functional adeno-associated virus-microdystrophin expression in the dystrophic CXMDj dog. J Gene Med. 2011;13:497-506.

191. Shin JH, Pan X, Hakim CH, Yang HT, Yue Y, Zhang K, et al. Microdystrophin ameliorates muscular dystrophy in the canine model of duchenne muscular dystrophy. Mol Ther. 2013;21:750-7.

192. Fan Z, Kocis K, Valley R, Howard JF, Chopra M, An H, et al. Safety and feasibility of high-pressure transvenous limb perfusion with $0.9 \%$ saline in human muscular dystrophy. Mol Ther. 2012;20:456-61.

193. Fan Z, Kocis K, Valley R, Howard Jr JF, Chopra M, Chen Y, et al. Highpressure transvenous perfusion of the upper extremity in human muscular dystrophy: a safety study with 0.9\% saline. Hum Gene Ther. 2015;26:614-21.

194. Yue Y, Pan X, Hakim CH, Kodippili K, Zhang K, Shin JH, et al. Safe and bodywide muscle transduction in young adult Duchenne muscular dystrophy dogs with adeno-associated virus. Hum Mol Genet. 2015;15: 5880-90.

195. Kornegay JN, Li J, Bogan JR, Bogan DJ, Chen C, Zheng H, et al. Widespread muscle expression of an AAV9 human mini-dystrophin vector after intravenous injection in neonatal dystrophin-deficient dogs. Mol Ther. 2010;18:1501-8.

\section{Submit your next manuscript to BioMed Central and we will help you at every step:}

- We accept pre-submission inquiries

- Our selector tool helps you to find the most relevant journal

- We provide round the clock customer support

- Convenient online submission

- Thorough peer review

- Inclusion in PubMed and all major indexing services

- Maximum visibility for your research

Submit your manuscript at www.biomedcentral.com/submit 